\author{
Universidade de São Paulo \\ FFCLRP - DEPARTAMENTO DE FÍSICA \\ Pós-GraduaÇÃo em Física aplicada À Medicina e Biologia
}

\title{
Verificação do uso do dosímetro Fricke benzóico xilenol gel em tomografia computadorizada
}

David Marçal Machado de Oliveira

Dissertação apresentada à Faculdade de Filosofia, Ciências e Letras de Ribeirão Preto da Universidade de São Paulo, como parte das exigências para a obtenção do título de Mestre em Ciências. Área: Física aplicada à Medicina e Biologia.

Ribeirão Preto - SP

2011 


\section{DAVID MARÇAL MACHADO DE OLIVEIRA}

\section{Verificação do uso do dosímetro Fricke benzóico xilenol gel em tomografia computadorizada}

Dissertação apresentada à Faculdade de Filosofia, Ciências e Letras de Ribeirão Preto da Universidade de São Paulo, como parte das exigências para a obtenção do título de Mestre em Ciências.

Área de Concentração:

Física aplicada à Medicina e Biologia.

\section{Orientadora:}

Profa. Dra. Adelaide de Almeida.

Versão corrigida

Versão original disponível na FFCLRP-USP

Ribeirão Preto - SP 
Autorizo a reprodução e divulgação total ou parcial deste trabalho, por qualquer meio convencional ou eletrônico, para fins de estudo e pesquisa, desde que citada a fonte.

\section{FICHA CATALOGRÁFICA}

Oliveira, David Marçal Machado de.

Verificação do uso do dosímetro Fricke benzóico xilenol gel em tomografia computadorizada/ David Marçal Machado de Oliveira; orientadora Profa. Dra. Adelaide de Almeida. Ribeirão Preto, 2011. 66 p.

Dissertação (Mestrado - Programa de Pós-Graduação em Física aplicada à Medicina e Biologia) - Faculdade de Filosofia, Ciências e Letras de Ribeirão Preto da Universidade de São Paulo.

1. Fricke Benzóico Xilenol Gel. 2. Dosimetria. 3. Tomografia Computadorizada. 
Nome: Oliveira, David Marçal Machado de

Título: Verificação do uso do dosímetro Fricke benzóico xilenol gel em tomografia computadorizada

Dissertação apresentada à Faculdade de Filosofia,

Ciências e Letras de Ribeirão Preto da

Universidade de São Paulo, como parte das exigências para a obtenção do título de Mestre em Ciências.

Aprovado em:

\section{Banca Examinadora}

Prof. Dr. :

Instituio:

Julgamento:

Assinatura:

Prof. Dr. :

Instituio:

Julgamento:

Assinatura:

Prof. Dr. :

Instituio:

Julgamento:

Assinatura: 


\section{Dedicatória}

Aos meus pais, Evaldo e Kátia, e meus irmãos, Diogo e Rebeca, pelo amor e apoio incondicional dispensados durante todo o período de mestrado. 


\section{Agradecimentos}

À Deus pelo sustento espiritual, mental e físico. Por ter me dado capacidade e

oportunidade de realizar esse mestrado. À Deus toda honra, glória e louvor! Amém!

À minha família, pais, irmãos, avós, tios e primos, que sempre me apoiaram e estiveram orando e torcendo pela minha vitória.

À Carolina de Resende Leão Ribeiro, por todo amor, carinho, paciência, amizade, fidelidade, companheirismo e espera (muita espera).

À Profa. Dra. Adelaide de Almeida pela orientação no mestrado e conhecimentos transmitidos.

Aos fiéis amigos e companheiros do laboratório RADIARE pela harmoniosa convivência durante esses três anos, por todo conhecimento compartilhado, pelos passeios juntos ("quem não foi mandou mal"), pelas boas risadas e gargalhadas. Jamais me esquecerei de vocês!

Aos amigos da República K-Zona, pela divertida convivência diária e pelos ensinamentos pessoais e culinários.

Aos amigos e colegas do Departamento de Física: Raúl, Mirko, Raimundo Nonato, Ebenézer (Bené), Jorge, José, Felipe Chen, Gustavo (Pudimm), Mairon.

Ao Tiago Giacometti, por tantas noites, ter me ajudado com as irradiações na CEDIRP.

Ao Sérgio Rocha da MS Medical Support pelas conversas esclarecedoras sobre meu trabalho, grande ajuda nos experimentos, confiança cedida quando emprestava objetos simuladores e câmara de ionização ...

Ao Roberto Pitorri pela ajuda no final do meu trabalho.

Ao Marcos Nakandakari por ter enviado os filmes Gafchromic necessários para realização desse trabalho.

À Nilza, secretária do Departamento de Física, pela ajuda desde a minha entrada 
no mestrado, arrumando papelada de matrícula e bolsa de estudos, até o final deste.

Aos técnicos Élcio Aparecido Navas, José Luiz Aziani e Sérgio Oliveira (Sérginho).

Ao Departamento de Física.

À CAPES pelo apoio financeiro. 
"Don't talk to me about X-rays,

I am afraid of them."

Thomas Alva Edison (1847 - 1931) 


\section{Resumo}

\section{OLIVEIRA, D. M. M. Verificação do uso do dosímetro Fricke benzóico}

xilenol gel em tomografia computadorizada. 2011. 66 p. Dissertação (Mestrado - Programa de Pós-Graduação em Física aplicada à Medicina e Biologia) - Faculdade de Filosofia, Ciências e Letras de Ribeirão Preto da Universidade de São Paulo. 2011.

A tomografia computadorizada (CT) representa a maior fonte de exposição aos raios $\mathrm{X}$ médicos e seu uso continua crescendo rapidamente, devido aos aparelhos de última geração com alta resolução de contraste. Uma avaliação dos parâmetros que influenciam a dose absorvida na tomografia asseguram o controle de qualidade e aceitação do equipamento. Os protocolos de CT utilizam câmara de ionização e filme radiográfico para esta avaliação e pela primeira vez, neste trabalho, o dosímetro químico Fricke Benzóico Xilenol Gel (FBXG) foi utilizado. Este dosímetro ao ser irradiado, produz um complexo colorido $\left(\mathrm{Fe}^{+3}-\mathrm{AX}\right)$ possível de ser medido através de técnicas ópticas, acústicas e de ressonância magnética. A leitura do filme e FBXG por fotografia, também foi empregada pela primeira vez neste trabalho indicando ser adequada. Da utilização do FBXG para avaliação do CT, foi possível obter os parâmetros de espessura de corte, homogeneidade de campo e curvas de isodose, além da promissora indicação dos índices de dose em tomografia.

Palavras-chave: 1. Fricke Benzóico Xilenol Gel. 2. Dosimetria. 3. Tomografia Computadorizada. 


\section{Abstract}

OLIVEIRA, D. M. M. Using the Fricke benzoic xylenol gel dosimeter on computed tomography. 2011. 66 p. Dissertation (M.Sc. - Postgraduate program in Physics applied to Medicine and Biology) - University of São Paulo Faculty of Philosophy, Sciences and Letters. 2011.

Computed tomography now represents the single largest source of medical exposure and its use is increasing rapidly, because of new generation units and hight contrast image. The acceptance and quality control tests of this equipment can be inferred through some parameters that influence the absorbed dose, such as axial and transaxial dose profile and CT dose indexes. Although ionization chamber and radiographic films are indicated by protocols for these evaluations, in this present work, beside this two dosimeters, we use the chemical dosimeter Fricke Benzoic Xylenol Gel (FBXG). This dosimeter when irradiated produces a colored complex $\left(\mathrm{Fe}^{+3}-\mathrm{XO}\right)$, that in this work was measured photographically to obtain the parameters, once this technique as well the FBXG are linearly dependent on the absorbed dose. This reading technique was adequate to obtain the calibration curve, the axial and transaxial dose profile for the FBXG, besides to let us visualize the future acquiring of tomographic dose indexes.

Key-words: 1. Fricke Benzoic Xylenol Gel. 2. Dosimetry. 3. Computed Tomography. 


\section{Lista de Figuras}

2.1 (a) Aparelho de primeira geração. Sistema de rotação/translação com geometria de feixe lápis. (b) Aparelho de segunda geração. Sistema de rotação/translação, conjunto de detectores e geometria de feixe leque. Adaptado de [40]. . . . . . . . . . . . . . . . . . . 5

2.2 (a) Aparelho de terceira geração. Sistema rotação/rotação com número de detectores aumentado para mais de 800. (b) Aparelho de quarta geração. Fonte rotaciona enquanto há um anel de detectores estacionários captando as informações. (c) Tecnologia slip-ring foi adicionada aos aparelhos de terceira e quarta geração. Tempo de exame diminui, pois após $360^{\circ}$ de rotação não é mais necessário parar a rotação para reverter a direção. Adaptado de [40] . . . . . . . . . . 6

2.3 (a) Baixo pitch: a mesa movimenta-se menos a cada revolução do tubo, proporcionando uma imagem com ótima resolução. (b) Alto pitch: a mesa se desloca muito para cada revolução do tubo, proporcionando uma imagem borrada. A "hélice" é esticada. O tempo de varredura em alto pitch é menor e isso reduz a dose ao paciente......................... 7

2.4 Sistema de detecção de tomógrafos com detectores únicos (esquerda) e multidetectores (direita) [12] . . . . . . . . . . . . . 8

2.5 A espessura da fatia no detector único (esquerda) é determinada pela colimação do feixe. À direita, tem-se multidetectores numa mesma fileira fazendo com que a espessura da fatia seja determinada pelo número de detectores usados $[41] \ldots \ldots$. . . . . . . . . . . . 9 
2.6 Vários desings de conjunto de detectores usados em tomógrafos multislice [40]. . . . . . . . . . . . . . . . . . . . . . . . 9

2.7 O tubo de raios $\mathrm{X}$ rotaciona continuamente enquanto o paciente movimenta-se a uma taxa constante.(a) Sistema de única fatia em CT helical. (b) CT helical multislice. . . . . . . . . . . . . . . . . . . 10

2.8 (a) Gradiente de dose resultante de uma exposição radiográfica na qual a fonte é estacionária em uma posição. As linhas mais espessas representam a dose de entrada na pele, a qual é muito maior do que a dose de saída na pele. Esta diferença cria um gradiente linear através do paciente. (b) Gradiente de dose resultante de uma rotação completa do tubo de raios $\mathrm{X}$ em um tomógrafo. As linhas mais espessas representam a dose de entrada na pele, a qual é muito maior do que a dose nos raios internos, linhas mais finas. Esta diferença resulta em um gradiente de dose radialmente simétrico dentro do paciente. . . . . . . . . . . . . . . . . . 11

2.9 (a) Medida típica de dose em um objeto simulador de acrílico de 32 cm de diâmetro. Valores medidos no centro e na periferia, $1 \mathrm{~cm}$ abaixo da superfície, mostram um gradiente de dose a uma taxa 2 : 1. (b) Medida típica da dose em um objeto simulador de acrílico de $16 \mathrm{~cm}$ de diâmetro. Valores medidos no centro e na periferia, $1 \mathrm{~cm}$ abaixo da superfície, não apresentam gradiente de dose. . . . . . . . . . . 12

2.10 Ilustração de geometria típica de um sistema de CT, sistema de coordenadas usadas e perfil de dose obtido de um único corte [55] . . 12

$2.11 \mathrm{O}$ efeito fotoelétrico ocorre quando um raio $\mathrm{X}$ incidente é totalmente absorvido durante a ionização de um elétron da camada atômica mais interna. O fóton incidente desaparece, e o elétron da camada-K, agora chamado de fotoelétron, é ejetado do átomo [11] . . . . . . . . . . . . 14

2.12 O efeito Compton ocorre entre raios X de energia moderada e elétrons da camada atômica mais externa. Ele resulta na ionização do átomo alvo, mudança da direção do fóton, e redução da energia do fóton. O comprimento de onda dos raios $\mathrm{X}$ espalhados é maior do que aqueles raios $\mathrm{X}$ incidentes $[11] \ldots \ldots \ldots$ 
2.13 Perfil de dose de um único corte feito em CT com o sensor de radiação posto no centro do objeto simulador. A cauda da dose (penumbra) é devida ao espalhamento Compton. . . . . . . . . . . . . . . . . 18

2.14 Soma de vários perfis de corte dados, um ao lado do outro. O MSAD é o valor médio das intensidades de dose individuais de cada corte, representado na figura pela linha sólida paralela ao eixo- $z$. . . . . . 18

2.15 Elétron armadilhado por outras moléculas de água. A parte positiva das moléculas de água estão mais próximas do elétron, enquanto que as partes negativas se encontram mais afastadas deste. Este arranjo é chamado de elétron aquoso e ele é detectado, pois possui forte absorção em $720 \mathrm{~nm}$. . . . . . . . . . . . . . . . . . . . . 22

3.1 Objetos simuladores de (a) cabeça e (b) abdômen que foram preenchidos com o dosímetro FBXG para avaliação das curvas de isodose e dos índices de dose tomográficos. . . . . . . . . . . . . . . . 24

3.2 Dois objetos espalhadores circulares de $16 \mathrm{~cm}$ de diâmetro e $70 \mathrm{~mm}$ de espessura e quatro elípticos de acrílico maciços cada um com 19, 4 × $29,5 \mathrm{~cm}^{2}$ e $15 \mathrm{~mm}$ de espessura. . . . . . . . . . . . . . . 25

3.3 (a) Objeto simulador preenchido com o dosímetro FBXG entreposto aos objetos espalhadores com mesma dimensão. (b) Objetos simuladores padrão em CT com 16 e 32 cm de diâmetro. . . . . . . . 25

3.4 Cubetas (a) padrão e (b) retangular utilizdas para curva de calibração e avaliação da espessura e homogeneidade de corte, respectivamente. . 27

3.5 Esquema do funcionamento do sistema de leitura fotográfico. . . . . . 29

4.1 Curvas de calibração obtidas para os dosímetros (a) filme e (b) FBXG através da irradiação de várias amostras de cada dosímetro. Para o filme foram usados os métodos de avaliação de densitometria óptica e fotografia. Para o FBXG utilizou-se apenas fotografia. . . . . . . . 31

4.2 Medições espectrofotométricas dos dosímetros químicos (a) Fricke gel e (b) filme radiocrômico em função do comprimento de onda e dose absorvida de um feixe de radiação. . . . . . . . . . . . . . . . . . 33 
4.3 Resultados da avaliação da homogeneidade das espessuras de corte, utilizando os dosímetros filme radiocrômico e FBXG. . . . . . . . . . 33

4.4 Perfis axiais de cortes de feixes do CT para os dosímetros FBXG e filme, variando a espessura de corte. . . . . . . . . . . . . . . . 34

4.5 Distribuição da dose absorvida (a) no filme radiocrômico e (b) no FBXG, para o objeto simulador de $16 \mathrm{~cm}$ de diâmetro. . . . . . . . . 36

4.6 Distribuição da dose absorvida no filme radiocrômico quando inserido entre os objetos espalhadores elípticos de acrílico. . . . . . . . . . . 37

4.7 Distribuição da dose absorvida no objeto simulador homogêneo de abdômen, preenchido com o dosímetro FBXG. . . . . . . . . . . . 37

4.8 Cinco regiões de interesse localizadas nos objetos simuladores de abdômen e cabeça. . . . . . . . . . . . . . . . . . . . . . . 38 


\section{Lista de Tabelas}

2.1 Distâncias percorridas por elétrons energéticos em meios de diferentes números atômicos e densidades físicas [30]. . . . . . . . . . . . 15

2.2 Energias de fótons espalhados por efeito Compton defletidos através de $90^{\circ}$ e $180^{\circ}$. A diferença da energia entre fótons incidentes e espalhados é transferida para o elétron-Compton espalhado [30]. . . . 17

2.3 Número de elétrons por grama para vários materiais [37] . . . . . . . 17

4.1 Valores nominais da espessura de corte do aparelho de CT comparados com os valores de FWHM medidos, associados às suas incertezas, para o filme radiocrômico e o FBXG. . . . . . . . . . . . . 35

4.2 Absorbâncias relativas inferidas das imagens fotográficas dos filmes radiocrômicos e dos objetos simuladores preenchidos com FBXG, considerando as cinco regiões de interesse. . . . . . . . . . . . . 38

4.3 Índices de dose tomográficos inferidos das imagens fotográficas dos filmes radiocrômicos e dos objetos simuladores (circular e elípticos) preenchidos com FBXG, considerando as cinco regiões de interesse. 39

4.4 Valores dos índices de dose em tomografia calculados a partir dos valores medidos da dose absorvida $\left(\mathrm{D}_{\mathrm{abs}}\right)$ nos objetos simuladores de CT com a câmara de ionização. Os valores de dose e dos índices estão em mGy. Os parâmetros utilizados foram de $120 \mathrm{kV}, 300 \mathrm{mAs}$ e 10 mm de espessura de corte. . . . . . . . . . . . . . . . . 40 


\section{Lista de Abreviaturas}

ANVISA Agência Nacional de Vigilância Sanitária.

AX Alaranjado de Xilenol (XO - Xylenol Orange).

CT Tomografia Computadorizada (Computed Tomography).

CTDI Índice de Dose em Tomografia Computadorizada (Computed Tomography Dose Index).

$\mathrm{CTDI}_{\mathrm{w}} \quad$ Índice de Dose em Tomografia Computadorizada médio (Computed Tomography Dose Index weighted).

$\mathrm{CTDI}_{100}$ Índice de Dose em Tomografia Computadorizada em $100 \mathrm{~mm}$ (Computed Tomography Dose Index $100 \mathrm{~mm}$ ).

FBXG Fricke Benzóico Xilenol Gel (Fricke Benzoic Xylenol Gel).

FXG Fricke Xilenol Gel (Fricke Xylenol Gel).

MSAD Dose Média de Múltiplos Cortes (Multiple Scan Average Dose).

OSL Luminescência Opticamente Estimulada (Optically Stimulated Luminescence).

ROI Região de Interesse (Region Of Interest).

TLD Dosímetro Termoluminescente (Thermoluminescent Dosimeter). 


\section{Sumário}

Lista de Figuras $\quad$ x

Lista de Tabelas $\quad$ xiv

Lista de Abreviaturas $\quad$ XV

1 Introdução 1

2 Aspectos Teóricos 4

2.1 Tomografia Computadorizada . . . . . . . . . . . . . . . . 4

2.2 Interação da Radiação com a Matéria em Baixas Energias . . . . . . 13

2.3 Avaliação da dose absorvida em CT . . . . . . . . . . . . . . . . . . . 17

2.4 Dosímetros . . . . . . . . . . . . . . . . . . 20

3 Materiais e Métodos $\quad 24$

3.1 Fonte de radiação e objetos simuladores . . . . . . . . . . . . . . . 24

3.2 Dosímetros Utilizados . . . . . . . . . . . . . . . . . 26

3.3 Métodos de Avaliações . . . . . . . . . . . . . . . . . . . . . . . 28

4 Resultados e Discussões 31

5 Conclusões $\quad 42$

Referências Bibliográficas $\quad 44$ 


\section{Capítulo}

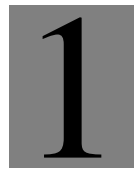

\section{Introdução}

O estudo do corpo humano permite compreender melhor as suas capacidades funcionais em um estado saudável ou doentio. A partir disso, pode-se detectar uma anormalidade (através de um diagnóstico), para a qual um tratamento ou terapia é utilizado para aliviar a dor ou restaurar o bem-estar do corpo.

O radiodiagnóstico faz uso de radiações ionizantes (raios X), em geral, em técnicas não invasivas para detectar possíveis anormalidades (em pacientes). O seu objetivo é produzir uma "imagem" na forma de sombras de vários tamanhos, formas e graus de enegrecimento, de tal forma que, ao examinar esta "imagem", o médico possa inferir a existência de qualquer anormalidade nas estruturas de interesse, relativa à cada sombra estudada [45]. Esta "imagem" é obtida devido às diferenças entre as composições, densidades e espessura das estruturas de interesse no paciente. As áreas de diferentes enegrecimentos num filme radiográfico são feitas utilizando equipamentos de raios $\mathrm{X}$, tais como raios $\mathrm{X}$ convencionais, angiografia, fluoroscopia, tomografia computadorizada (CT), mamografia, entre outros. Uma vez que esta ferramenta (raios X) tornou-se muito utilizada na prática médica, hospitais e clínicas são os maiores responsáveis pela exposição da radiação ionizante às pessoas, devido ao grande número de procedimentos diagnósticos [39].

Dentre os exames, aqueles envolvendo CT fornecem $40 \%$ da dose coletiva [32, 10], portanto, uma quantificação da dose nos exames em CT é também de relevante importância para avaliar o risco-benefício em pacientes [39, 26, 7]. Durante esses exames, a escolha dos parâmetros $\mathrm{kVp}$, pitch, espessura de corte, mAs, assim como a espessura do paciente, influenciam na dose absorvida [43]. No entanto, os aparelhos 
de CT possuem parâmetros pré-definidos para os diversos exames, baseados na escolha de um "paciente padrão". Deste modo, pacientes com volume corporal diferente daquele do padrão receberão doses diferentes da esperada para a realização dos exames [46].

No caso de exames feitos em crianças o problema citado é mais crítico, pois sendo que elas tem uma menor massa, incorporarão uma dose absorvida maior, implicando em um maior risco estocástico da radiação para efeitos genéticos e carcinogênicos [29], o que chama à atenção para a utilização do "conceito" ALARA (As Low As Reasonable Achievable, níveis de exposição tão baixos quanto possivelmente exequíveis), nos protocolos de CT com a preocupação com a dose recebida pelo paciente [18].

Para atender aos protocolos de CT na monitoração dos níveis de exposição nos exames, vários detectores podem ser empregados, como os a gás (câmara de ionização), os de estado sólido (termoluminescentes e semicondutores) e químicos (filmes) [35, 3].

Neste trabalho, além da câmara de ionização e filme, também foi utilizado o dosímetro Fricke Benzóico Xilenol Gel (FBXG), baseado em ácidos sulfúrico e benzóico, um marcador metálico (alaranjado de xilenol), uma gelatina de origem animal e $\left[\mathrm{Fe}^{+2}\right]$ que quando irradiado produz o complexo $\left[\mathrm{Fe}^{+3}-\mathrm{AX}\right]$, proporcional à dose absorvida da radiação. Esta gelatina, após irradiada, fornece uma localização espacial das mudanças induzidas pela radiação, com pico de absorção máximo em $585 \mathrm{~nm}$, que podem ser medidas através das técnicas de espectrofotometria visível [5], fotoacústica $[14,15]$, imagens com um sensor CCD $[21,53]$ e tomografia de absorção óptica [36, 6].

A utilização dos dosímetros químicos filme e FBXG no controle de qualidade é complementar à câmara de ionização, visto que esta possui tamanho limitado e não consegue medir o perfil de corte e homogeneidade de campo, fazendo apenas uma leitura pontual da dose absorvida em uma determinada localização espacial.

Os dosímetros utilizados foram empregados para avaliar alguns parâmetros em CT que fazem parte de testes de controle de qualidade e aceitação do equipamento, tais como espessura de corte e homogeneidade de campo e os índices de dose em tomografia, Computed Tomography Dose Index $\left(\mathrm{CTDI}_{100}\right.$ e $\left.\mathrm{CTDI}_{\mathrm{w}}\right)[16,17]$, sendo 
que as medidas desses últimos parâmetros $\mathrm{CTDI}_{100}$ e $\mathrm{CTDI}_{\mathrm{w}}$ nos permitiram inferir as distribuições da dose absorvida para diferentes dimensões de pacientes. Dos resultados obtidos pudemos verificar que com o FBXG é possível realizar medidas em CT para obtenção da maioria dos parâmetros citados, assim demonstrando sua capacidade e o potencial de uso deste dosímetro.

As noções teóricas necessárias para o desenvolvimento deste trabalho são apresentadas no Capítulo 2 e no Capítulo 3, os materias e métodos utilizados. No Capítulo 4 estão os resultados obtidos em paralelo com as discussões pertinentes e no Capítulo 5, finalizamos com as conclusões inferidas do trabalho. 


\section{Capítulo}

\section{Aspectos Teóricos}

\subsection{Tomografia Computadorizada}

A técnica de reconstrução de imagem usada na tomografia teve vários precursores. O primeiro deles foi Johann Radon, em 1917, o qual em seu artigo [48] demonstrou que infinitas projeções de um objeto desconhecido podem ser usadas para reconstruí-lo. Em teoria de probabilidades, este problema foi desenvolvido por Cramér e Wold em 1936 [19]. Talvez o precursor mais incomum foi Bracewell [8], que correlacionou o teorema de Radon à reconstrução de regiões emissoras de microondas provenientes do Sol. DeRosier e Klug usaram uma técnica semelhante em microscopia eletrônica para reconstruir a estrutura tridimensional da cauda do bacteriófago T4 (vírus que pode infectar bactérias e até mesmo digerí-las, através de uma enzima capaz de perfurar a parede celular bacteriana) [20], trabalho que colaborou para que Klug ganhasse o prêmio Nobel em Química em 1982.

O primeiro aparelho de CT, EMI MARK 1 (1972), realizava apenas exames de cabeça. Foi classificado como um tomógrafo de primeira geração. Todos os aparelhos desta linha possuíam 2 detectores que transladavam e rotacionavam juntamente com a fonte de radiação para produzir e detectar um feixe tipo lápis (Figura 2.1(a)). A vantagem de se utilizar esta geometria é que aumenta a eficiência na redução do espalhamento medido pelos detectores. Cada par de fatias levava 4,5 minutos de varredura, mais 1,5 minutos para que sua imagem pudesse ser reconstruída. A invenção deste equipamento rendeu um prêmio Nobel em Fisiologia na Medicina em 1979 para Godfrey Hounsfield, engenheiro britânico, e Alan Cormack, físico 
americano.

Os aparelhos de CT representam um casamento de diversas tecnologias como hardware de computadores, sistemas de controle motor, detectores de raios X, algoritmos de construção sofisticados e sistemas de tubo/geradores de raios X. O desenvolvimento dessas tecnologias propiciou o avanço dos aparelhos de CT e quanto maior suas eficiências, mais caros se tornavam.

A segunda geração de CT possuía um sistema de rotação/translação combinado com um feixe estreito no formato de leque $\left(10^{\circ}\right.$ abertura). Nesses aparelhos foi incorporado um conjunto linear de 30 detectores ao invés de 2, nos de primeira geração (Figura 2.1(b)). Com isto, obteve-se um tempo de varredura 15 vezes mais rápido, levando 18 segundos por fatia.

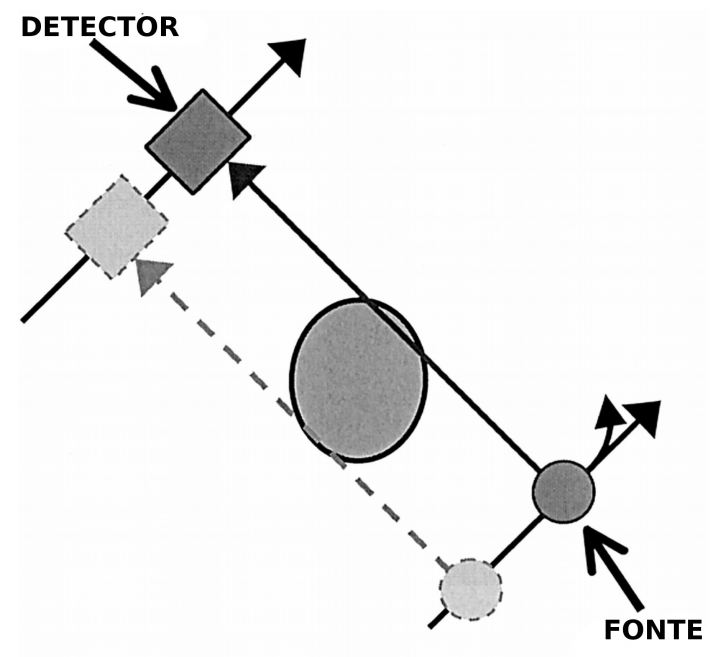

(a)

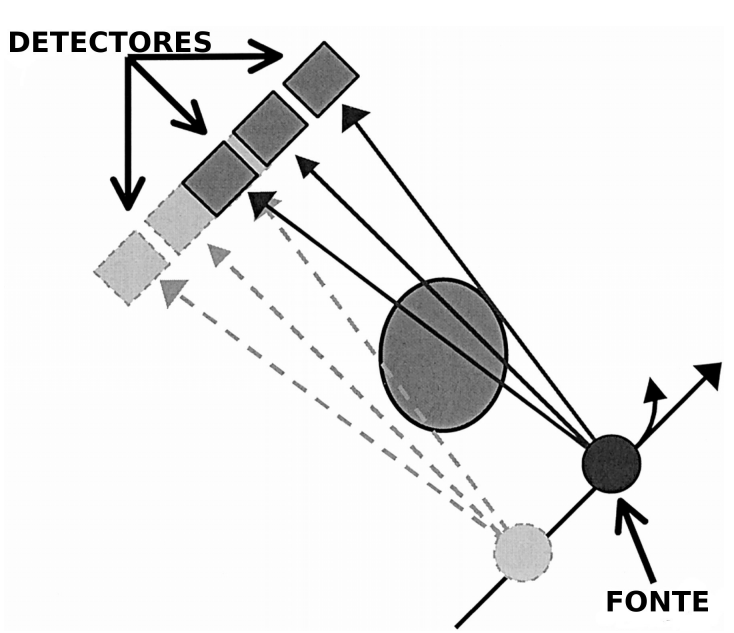

(b)

Figura 2.1. (a) Aparelho de primeira geração. Sistema de rotação/translação com geometria de feixe lápis. (b) Aparelho de segunda geração. Sistema de rotação/translação, conjunto de detectores e geometria de feixe leque. Adaptado de [40].

O número de detectores foi aumentado consideravelmente (mais de 800 detectores) para os aparelhos de terceira geração. Esses usavam um sistema combinado de rotação tubo e feixe, no qual este último era bem aberto e na forma de leque, ou seja, o tubo de raios $\mathrm{X}$ e o conjunto de detectores rotacionavam ao mesmo tempo em volta do paciente, sem translação (Figura 2.2(a)), o que reduziu o tempo de varredura para 5 segundos. 
No final dos anos 70 surgiu o tomógrafo de quarta geração com um sistema no qual o tubo de raios $\mathrm{X}$ rotacionava enquanto um anel estacionário de detectores, ao redor do paciente (aproximadamente 4.800 detectores individuais), realizava as medidas (Figura 2.2(b)).

No início dos anos 90 os tomógrafos de terceira e quarta geração incorporaram a tecnologia slip ring (anel deslizante), a qual é livre de fios conectados ao tubo de raios X e detectores. Nesta tecnologia a corrente é passada através de contatos que deslizam em um anel condutor. Desta forma, após a rotação completa, não é mais necessário o tubo reverter a direção de rotação, permitindo tempos menores nos exames (Figura 2.2(c)).

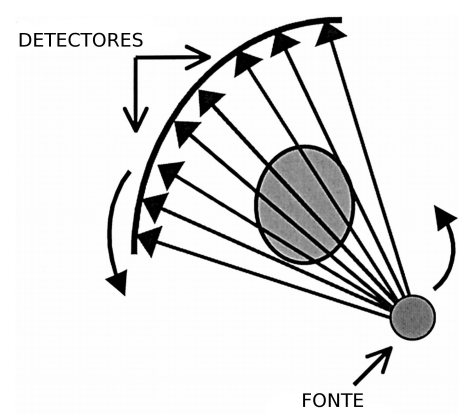

(a)

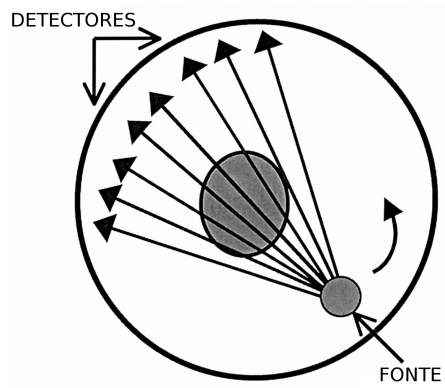

(b)

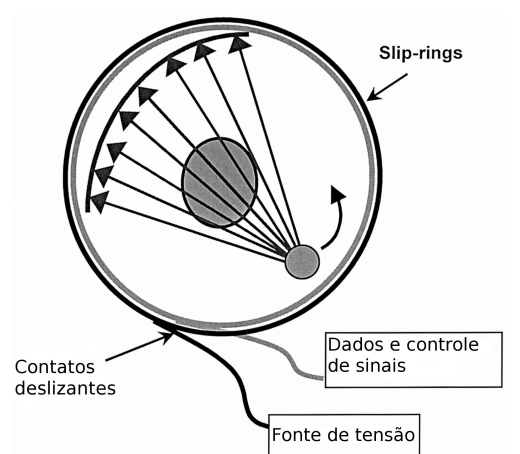

(c)

Figura 2.2. (a) Aparelho de terceira geração. Sistema rotação/rotação com número de detectores aumentado para mais de 800. (b) Aparelho de quarta geração. Fonte rotaciona enquanto há um anel de detectores estacionários captando as informações. (c) Tecnologia slip-ring foi adicionada aos aparelhos de terceira e quarta geração. Tempo de exame diminui, pois após $360^{\circ}$ de rotação não é mais necessário parar a rotação para reverter a direção. Adaptado de [40].

A quinta geração, também conhecida como tomografia computadorizada por feixe de elétrons, foi desenvolvida especificamente para imagens tomográficas do coração. Nesta não se usa um tubo de raios X convencional, mas um feixe de elétrons que é produzido por um canhão de elétrons e é orientado para se chocar com um arco de $210^{\circ}$ de tungstênio situado no lado oposto ao detector. Este aparelho pode ser configurado para funcionar em cine mode, para o qual o tempo de varredura é de 50 ms, capaz de produzir filmes do coração em movimento.

A sexta geração é aquela correspondente à tomografia computadorizada helicoidal. Esses aparelhos são capazes de obter os dados enquanto a mesa está em 
movimento, logo, a fonte de raios $\mathrm{X}$ move-se helicoidalmente ao redor do paciente, que está sendo examinado. A relação que descreve o movimento da mesa e a rotação do tubo de raios $\mathrm{X}$ é dada por um parâmetro chamado pitch (passo), veja Figuras 2.3(a) e 2.3(b). A equação para avaliar este parâmetro é

$$
\text { Pitch }=\frac{T}{W},
$$

sendo $T$ o quanto a mesa anda (passo) por uma rotação completa do tubo de raios $\mathrm{X}$ e $W$ a espessura de corte da fatia.

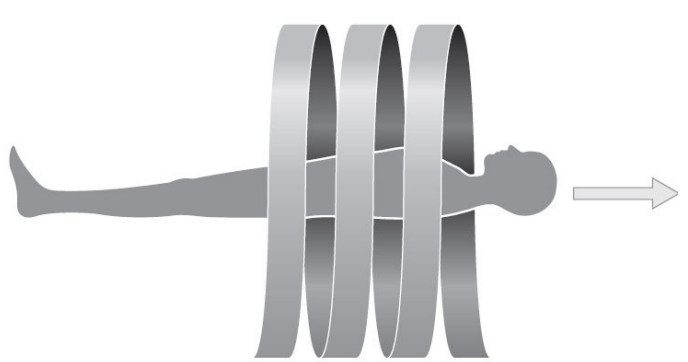

(a)

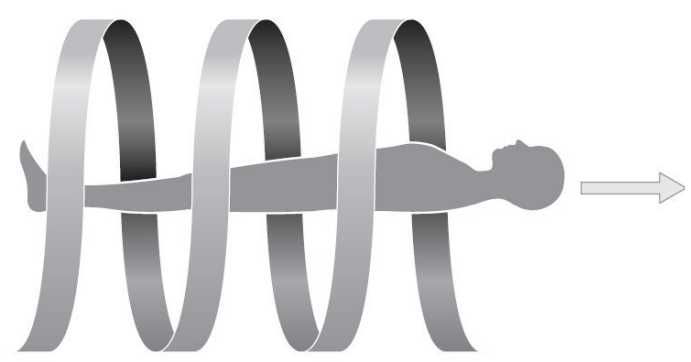

(b)

Figura 2.3. (a) Baixo pitch: a mesa movimenta-se menos a cada revolução do tubo, proporcionando uma imagem com ótima resolução. (b) Alto pitch: a mesa se desloca muito para cada revolução do tubo, proporcionando uma imagem borrada. A "hélice" é esticada. O tempo de varredura em alto pitch é menor e isso reduz a dose ao paciente.

O grande avanço da tecnologia dos aparelhos tomográficos foi a introdução de múltiplos detectores. Isto ocorreu na sétima geração, conhecida como MDCT (Multidetector CT) ou tomógrafo Multislice, que conta com vários conjuntos de detectores alinhados em toda circunferência do gantry.

Nos tomógrafos com o conjunto de detectores únicos, a espessura da fatia é determinada pela colimação do feixe de raios X, gerando uma fatia por revolução do tubo. Conforme o espaço entre os colimadores é aumentado, a espessura da fatia também aumenta. No entanto, o espaço entre os colimadores deve ser sempre menor que a largura máxima do detector, Figura 2.4.

Em um MDCT a espessura da fatia não é determinada pela abertura do colimador (apesar deste colimar o feixe de raios X para a espessura total do corte), mas sim pela largura de um detector ou da largura da combinação de dois ou mais detectores na espessura total do corte. No tomógrafo multislice várias fatias são 


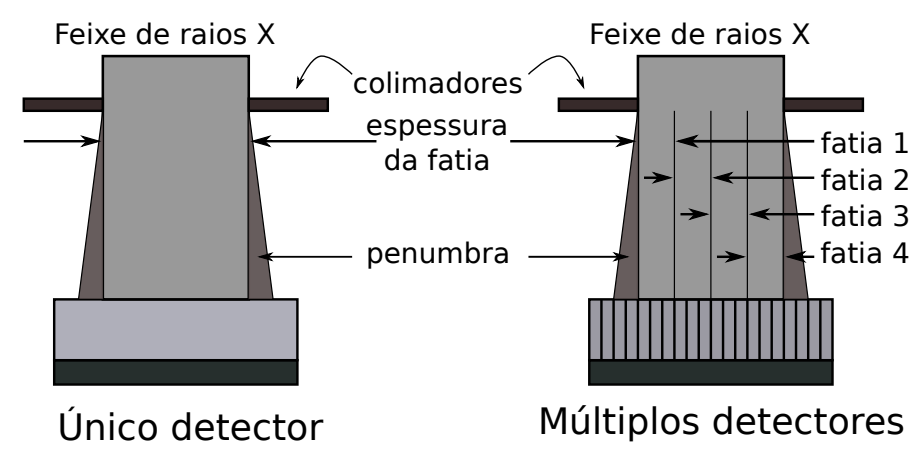

Figura 2.4. Sistema de detecção de tomógrafos com detectores únicos (esquerda) e multidetectores (direita) [12].

adquiridas simultaneamente. Na Figura 2.4, temos quatro fatias em um único corte e três detectores foram combinados para formar cada fatia. A abertura do colimador define apenas o limite das fatias localizadas nas extremidades e o volume a ser irradiado.

$\mathrm{Na}$ Figura 2.5 tem-se como exemplo pictórico, a organização dos detectores nos tomógrafos a partir da quarta geração (esquerda) e nos de sétima geração (direita), ambos com uma espessura total de detecção de $20 \mathrm{~mm}$. No sistema de multidetectores, sistema de 16 elementos individuais de 1,25 mm, uma espessura total de corte de $10 \mathrm{~mm}$ é produzida por oito elementos em uma revolução completa do tubo, fornecendo oito fatias de $1,25 \mathrm{~mm}$ por corte/revolução do tubo. Uma combinação de dois elementos ou mais elementos pode ser feita para uma mesma espessura de corte. A combinação de dois elementos deste sistema, por exemplo, produz quatro fatias de $2,5 \mathrm{~mm}$ por corte/revolução do tubo. No aparelho de detectores únicos, apenas uma fatia de $10 \mathrm{~mm}$ é produzida por corte/revolução do tubo determinada pela colimação do feixe.

A configuração dos detectores nos aparelhos MDCT pode variar conforme o fabricante. Na Figura 2.6 tem-se diferentes configurações de múltiplos detectores para vários fabricantes, nas quais, em alguns casos, os detectores apresentam até espessuras diferentes.

As máquinas multislice utilizam também o princípio do tomógrafo helicoidal, no entanto, se diferenciam pelo sistema de múltiplos detectores. Esses podem então, adquirir múltiplas fatias por rotação do tubo, aumentando a área do paciente que pode ser coberta (num dado tempo) pelo feixe de raios X (Figura 2.7(b)). Nos 


\section{Conjunto de Detectores Únicos}

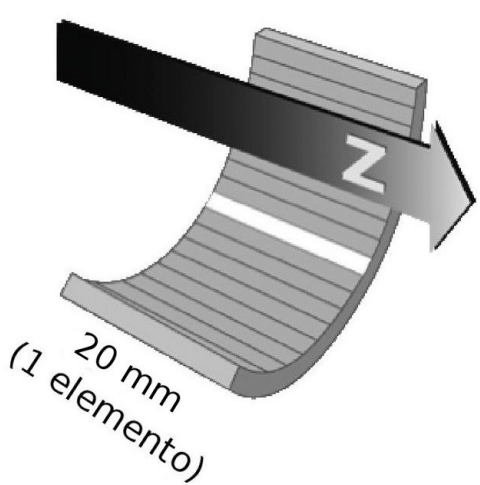

4a geração

\section{Conjunto de \\ Detectores Múltiplos}

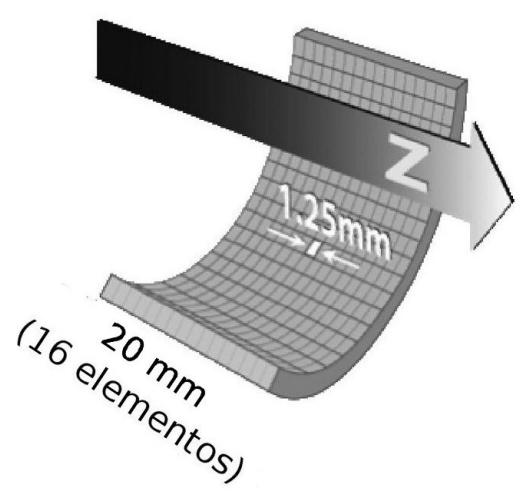

7ạ geração

Figura 2.5. A espessura da fatia no detector único (esquerda) é determinada pela colimação do feixe. À direita, tem-se multidetectores numa mesma fileira fazendo com que a espessura da fatia seja determinada pelo número de detectores usados [41].

GE/Philips

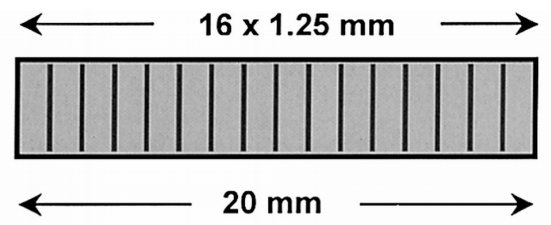

Siemens
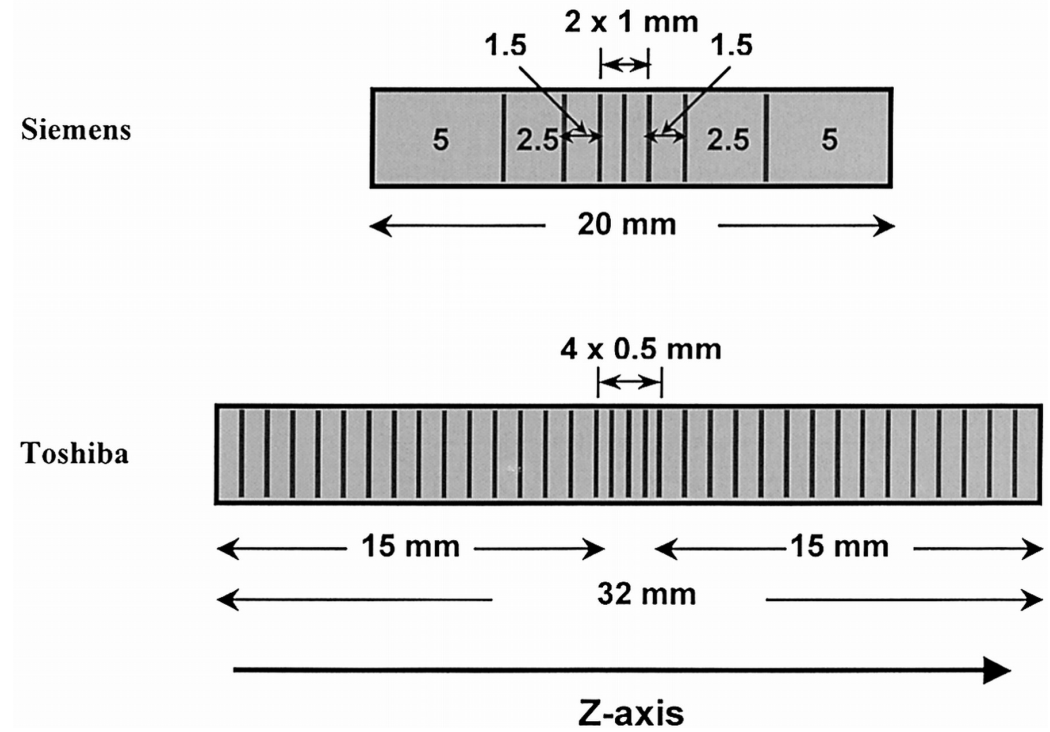

Figura 2.6. Vários desings de conjunto de detectores usados em tomógrafos multislice [40]. 
scanners helicoidais, onde há apenas um anel detector, a área é bem menor para um mesmo tempo de exame (Figura 2.7(a)).

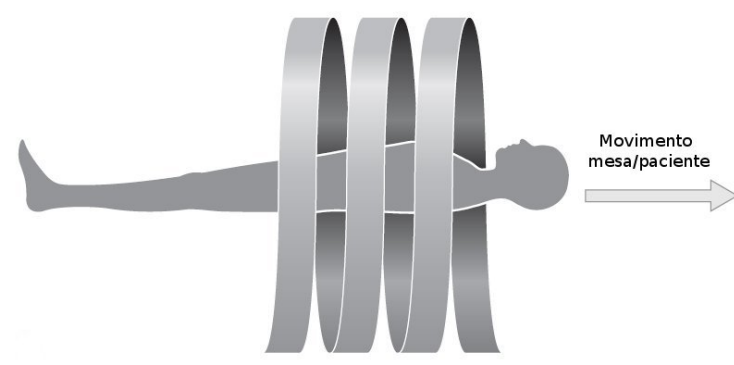

(a)

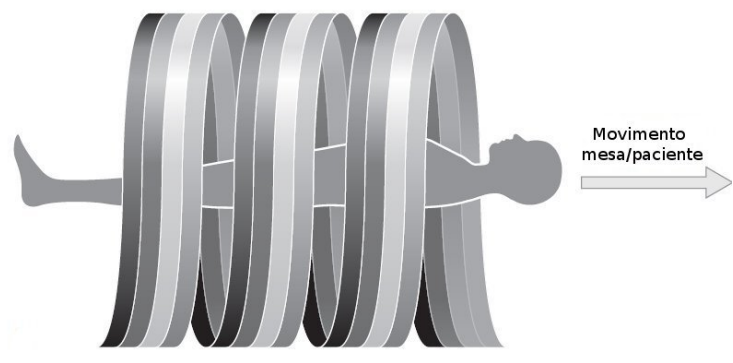

(b)

Figura 2.7. $\mathrm{O}$ tubo de raios $\mathrm{X}$ rotaciona continuamente enquanto o paciente movimenta-se a uma taxa constante.(a) Sistema de única fatia em CT helical. (b) CT helical multislice.

Todo desenvolvimento de uma geração para outra influenciou na rapidez de aquisição de dados, melhorias nas imagens (resolução espacial), menor tempo computacional para reconstrução das imagens e menor dose absorvida ao paciente. No entanto, por ser uma técnica bastante utilizada na prática clínica, a dose coletiva administrada por exames em aparelhos de CT é maior do que aquela por exames em raios $\mathrm{X}$ convencionais. Além do mais, o próprio exame de $\mathrm{CT}$ excede em dose em relação àqueles por radiografia convencional devido a três aspectos:

- alta colimação do feixe em CT: o volume de tecido/objeto irradiado é muito menor;

- o volume de tecido/objeto irradiado é exposto ao feixe de raios $\mathrm{X}$ em todos os ângulos devido à rotação do tubo, logo, a dose de radiação é bem distribuida nesse volume;

- alto contraste de resolução: a dose de radiação ao volume da fatia é mais alta devido aos parâmetros utilizados ( $\mathrm{kV}$ e mAs) serem mais altos. Uma típica radiografia de tórax utiliza parâmetros de $120 \mathrm{kV}$ e $5 \mathrm{mAs}$, enquanto que um CT toráxico é adquirido usando $120 \mathrm{kV}$ e 200 mAs.

Na radiografia convencional as exposições são feitas com a posição da fonte fixa e a dose de entrada na pele é muito maior que na saída dela, criando um gradiente 
de dose através do paciente (Figura 2.8(a)). Isto contrasta com a exposição em tomografia computadorizada para a qual o tubo de raios $\mathrm{X}$ rotaciona $360^{\circ}$ em torno do paciente, criando um gradiente de dose radialmente simétrico internamente a ele. Isto significa que num objeto simulador cilíndrico, todos os pontos em um mesmo raio do centro possuem, aproximadamente, a mesma dose de radiação (Figura 2.8(b)).

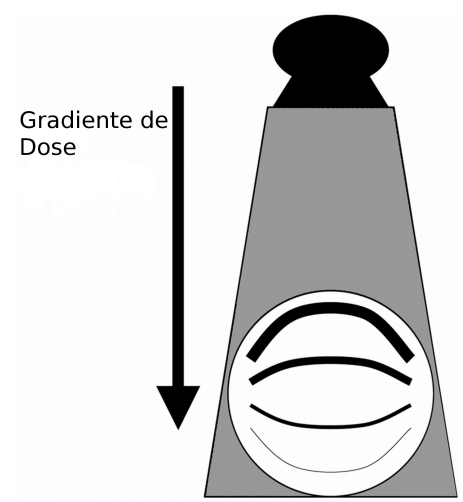

(a)

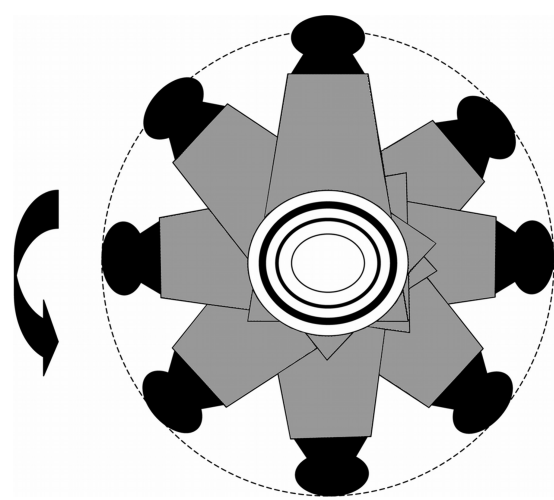

(b)

Figura 2.8. (a) Gradiente de dose resultante de uma exposição radiográfica na qual a fonte é estacionária em uma posição. As linhas mais espessas representam a dose de entrada na pele, a qual é muito maior do que a dose de saída na pele. Esta diferença cria um gradiente linear através do paciente. (b) Gradiente de dose resultante de uma rotação completa do tubo de raios $\mathrm{X}$ em um tomógrafo. As linhas mais espessas representam a dose de entrada na pele, a qual é muito maior do que a dose nos raios internos, linhas mais finas. Esta diferença resulta em um gradiente de dose radialmente simétrico dentro do paciente.

Quando se utiliza objetos simuladores de corpo (feitos de acrílico) para CT com $32 \mathrm{~cm}$ de diâmetro, as medidas de dose obtidas no centro são aproximadamente $50 \%$ relativas àquelas feitas na periferia (Figura 2.9(a)). No entanto, esta diferença pode ser afetada pelo tamanho do objeto simulador, espectro dos raios X e pela atenuação do material ou tecido. Sob as mesmas condições, um objeto simulador de acrílico com $16 \mathrm{~cm}$ de diâmetro apresenta o mesmo valor de dose no centro até sua periferia (Figura 2.9(b)). Portanto, há uma dependência da dose absorvida com o tamanho do objeto simulador [43].

Quando um objeto simulador cilíndrico é irradiado em um tomógrafo, Figura 2.10, a alta colimação do feixe e a geometria do sistema produz uma fatia neste objeto. Perpendicular a esta fatia, a medida da dose ao longo da linha AB, paralela ao eixo- $z$, pode ser usada para construir a distribuição da dose ou perfil da mesma 


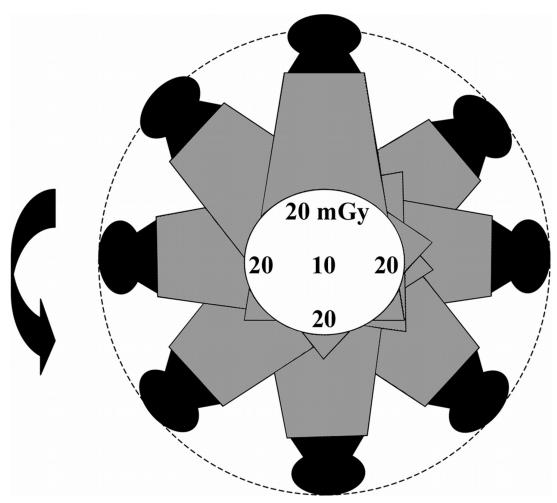

(a)

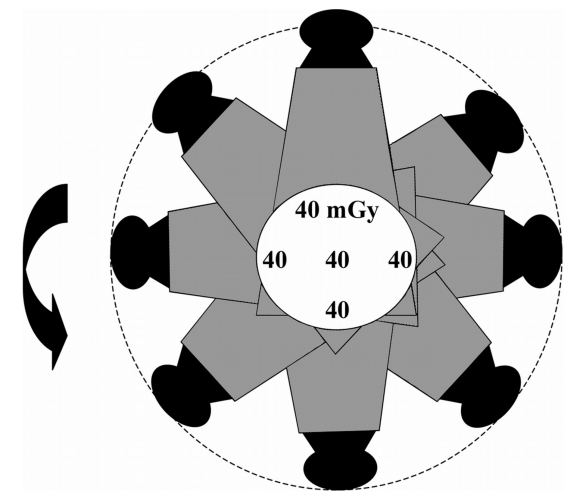

(b)

Figura 2.9. (a) Medida típica de dose em um objeto simulador de acrílico de $32 \mathrm{~cm}$ de diâmetro. Valores medidos no centro e na periferia, $1 \mathrm{~cm}$ abaixo da superfície, mostram um gradiente de dose a uma taxa $2: 1$. (b) Medida típica da dose em um objeto simulador de acrílico de $16 \mathrm{~cm}$ de diâmetro. Valores medidos no centro e na periferia, $1 \mathrm{~cm}$ abaixo da superfície, não apresentam gradiente de dose.

em função da posição. Devido aos raios X espalhados, o perfil da dose na fatia em estudo não é perfeitamente quadrado, mas possui uma cauda que se estende além da espessura da fatia, devido aos raios $\mathrm{X}$ espalhados.

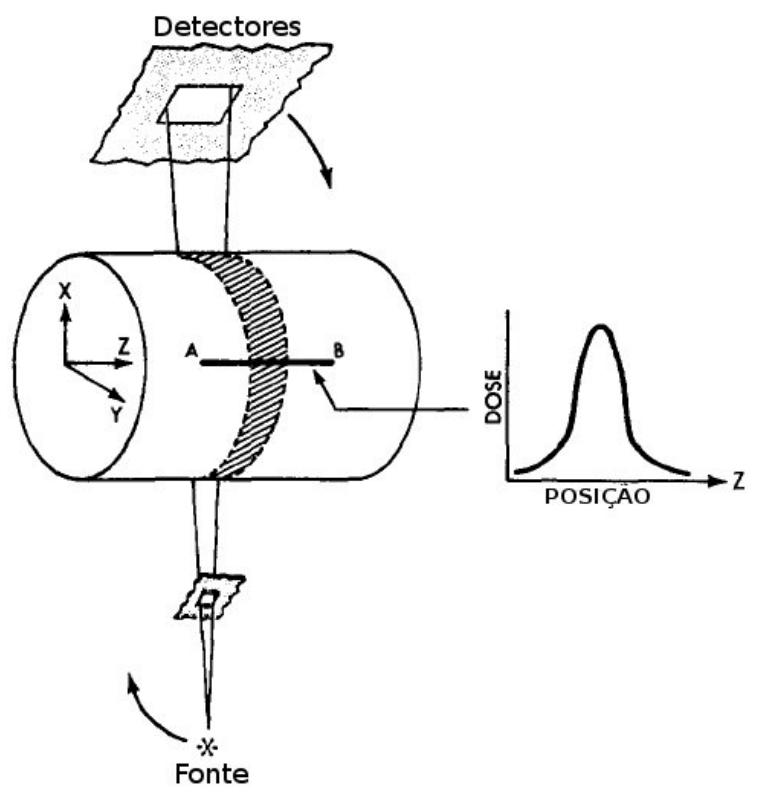

Figura 2.10. Ilustração de geometria típica de um sistema de CT, sistema de coordenadas usadas e perfil de dose obtido de um único corte [55].

A distribuição da dose absorvida está relacionada à interação da radiação com a matéria que é dependente do feixe, sua energia e geometria da radiação, como 
também da geometria e material do objeto irradiado. Os principais efeitos da interação da radiação fotônica com a matéria para energia do feixe utilizado em CT são o fotoelétrico e o Compton. O efeito Rayleigh, apesar de ocorrer no intervalo da energia considerado, não merecerá atenção neste trabalho, uma vez que a sua contribuição para o coeficiente de atenuação do feixe terá porcentagem de $5 \%$ ou menor $[11,3]$ e por não contribuir com a deposição de dose no meio incidente.

\subsection{Interação da Radiação com a Matéria em Energias do Radiodiagnóstico}

A radiação eletromagnética interage com estruturas similares ao seu comprimento de onda. Raios X possuem comprimentos de onda muito pequenos, não muito maiores do que $10^{-8}$ a $10^{-9} \mathrm{~m}$. Quanto maior a energia do raio X, menor será seu comprimento de onda. Consequentemente, raios $\mathrm{X}$ de baixas energias tendem a interagir com átomos, os quais têm diâmetro de aproximadamente $10^{-9}$ a $10^{-10} \mathrm{~m}$; raios $\mathrm{X}$ de energia moderada geralmente interagem com a nuvem eletrônica do átomo; e raios X de alta energia geralmente interagem com o núcleo atômico.

Há cinco mecanismos pelos quais a radiação eletromagnética interage com matéria: espalhamento Rayleigh, efeito Compton, efeito fotoelétrico, produção de pares e interações fotonucleares. Os de particular importância para o radiodiagnóstico são o efeito Compton e o efeito fotoelétrico, que ocorrem na faixa de energia de $15-150 \mathrm{keV}$.

O efeito fotoelétrico é o fenômeno no qual o fóton incidente interage com um elétron fortemente ligado (camada K ou L), absorvendo toda a energia do fóton e, consequentemente, ejetando o elétron (Figura 2.11). O elétron ejetado é chamado de fotoelétron e possui energia cinética $T_{e}$ igual a

$$
T_{e}=h \nu-E_{b},
$$

sendo $h \nu$ a energia do fóton incidente e $E_{b}$ a energia de ligação do elétron. Este tipo de interação somente ocorre quando o fóton incidente possui uma energia igual ou superior à energia de ligação do elétron no átomo. O fotoelétron perde sua energia ionizando outros átomos no tecido, contribuindo assim para a dose no paciente. 


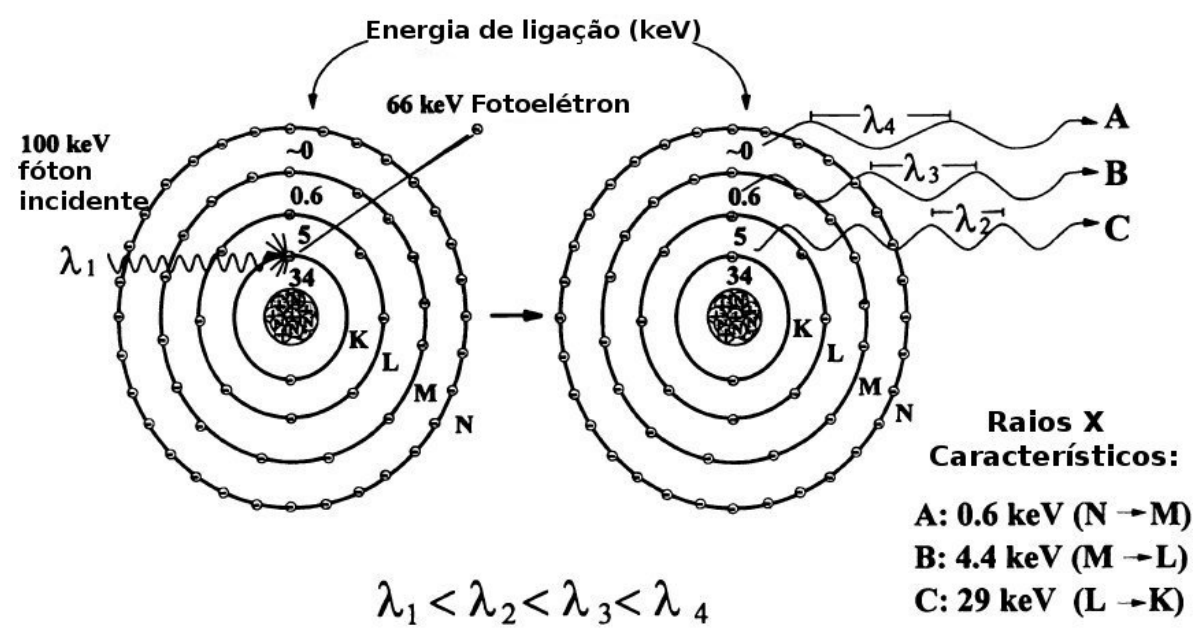

Figura 2.11. O efeito fotoelétrico ocorre quando um raio $\mathrm{X}$ incidente é totalmente absorvido durante a ionização de um elétron da camada atômica mais interna. O fóton incidente desaparece, e o elétron da camada-K, agora chamado de fotoelétron, é ejetado do átomo [11].

O átomo, agora em estado excitado, tem sua vacância preenchida por um elétron de uma camada mais externa. Neste processo, um raio X característico é emitido, podendo ser absorvido internamente pelo átomo e emitindo elétrons Auger, que são elétrons monoenergéticos. Em tecidos moles a energia de ligação da camada K é $\sim 0,5 \mathrm{keV}$, logo, os fótons característicos produzidos em absorvedores biológicos possuem energia muito baixa e são totalmente absorvidos no meio. Para fótons de alta energia e materiais de alto número atômico, a radiação característica é de alta energia e pode ser depositada a grandes distâncias, comparadas com o alcance do fotoelétron. Neste caso, pode acontecer uma redução da energia local absorvida quando a energia emitida é uma radiação característica (também chamada de radiação fluorescente), a qual tem probabilidade remota de ser absorvida.

A probabilidade de absorção fotoelétrica depende da energia do fóton e do meio absorvedor como

$$
\frac{\tau}{\rho} \propto \frac{Z^{3 \rightarrow 4}}{E^{3}},
$$

sendo $\tau / \rho$ o coeficiente de atenuação de massa fotoelétrico, $Z$ o número atômico do material absorvedor e $E$ a energia do fóton incidente. Quanto menor a energia do fóton incidente e maior o número atômico $Z$ do material absorvedor, maior será a probabilidade de absorção do fóton incidente por efeito fotoelétrico. A relação com o número atômico é a base nos exames de radiodiagnóstico. Na Tabela 2.1 temos 
as distâncias máximas, ou alcances, percorridas por elétrons até serem absorvidos, com as energias utilizadas no radiodiagnóstico.

Tabela 2.1. Distâncias percorridas por elétrons energéticos em meios de diferentes números atômicos e densidades físicas [30].

\begin{tabular}{cccc}
\hline \hline $\begin{array}{c}\text { Energia do elétron } \\
(\mathrm{keV})\end{array}$ & $\begin{array}{c}\text { Ar* }^{*} \\
(\mathrm{~cm})\end{array}$ & $\begin{array}{c}\text { Água }^{\dagger} \\
(\mu \mathrm{m})\end{array}$ & $\begin{array}{c}\text { Osso }^{\ddagger} \\
(\mu \mathrm{m})\end{array}$ \\
\hline 10 & 0,25 & 3 & 2 \\
30 & 1,7 & 18 & 12 \\
50 & 4,1 & 43 & 28 \\
100 & 13,5 & 140 & 94 \\
150 & 26,5 & 280 & 180 \\
\hline \hline
\end{tabular}

*Número atômico: 7,8; densidade física: $0,0012 \mathrm{~g} / \mathrm{cm}^{3}$. ${ }^{\dagger}$ Número atômico: 7,5 ; densidade física: $1,0 \mathrm{~g} / \mathrm{cm}^{3}$. ${ }^{\ddagger}$ Número atômico: 12,3 ; densidade física: $1,7 \mathrm{~g} / \mathrm{cm}^{3}$.

O efeito Compton ou espalhamento Compton é a interação de um fóton com um elétron "livre". O termo livre significa que a energia do fóton é muito maior que a energia de ligação do elétron. Nesta interação, o elétron recebe uma energia do fóton e é ejetado do átomo. O fóton, que pode ser tratado como uma esfera rígida, é espalhado inelasticamente num ângulo $\theta$ (Figura 2.12). Uma vez que o elétron-Compton é ejetado do átomo, ele perde sua energia cinética através de excitação e ionização de átomos na vizinhança do material, sendo o responsável pela deposição local da energia do feixe de fótons. O fóton-Compton espalhado, por outro lado, pode atravessar todo o material, sem interação, ou pode sofrer qualquer tipo de interação fotônica, incluindo um subsequente espalhamento Compton, absorção fotoelétrica, ou, se a energia do fóton for baixa, espalhamento Rayleigh.

Analisando a colisão entre o fóton e o elétron e aplicando as leis de conservação de energia e momentum, pode-se chegar ao conjunto de equações abaixo:

$$
\begin{aligned}
E_{e} & =E_{0} \frac{\alpha(1-\cos \theta)}{1+\alpha(1-\cos \theta)}, \\
E_{s c} & =E_{0} \frac{1}{1+\alpha(1-\cos \theta)},
\end{aligned}
$$




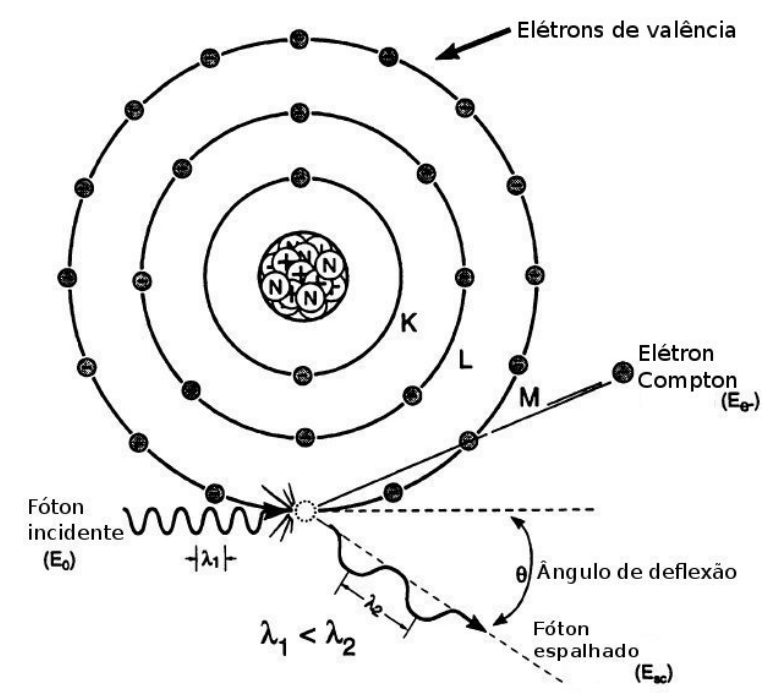

Figura 2.12. O efeito Compton ocorre entre raios $X$ de energia moderada e elétrons da camada atômica mais externa. Ele resulta na ionização do átomo alvo, mudança da direção do fóton, e redução da energia do fóton. O comprimento de onda dos raios $\mathrm{X}$ espalhados é maior do que aqueles raios $\mathrm{X}$ incidentes [11].

$$
\operatorname{cotg} \phi=(1+\alpha) \operatorname{tg}(\theta / 2)
$$

sendo $E_{0}, E_{s c}$, e $E_{e}$ as energias do fóton incidente, fóton espalhado, e elétron, respectivamente, e $\alpha=E_{0} / m_{0} c^{2}$, com $m_{0} c^{2}$ sendo a energia de repouso do elétron $(0,511 \mathrm{MeV})$. $\phi$ é o ângulo no qual o elétron foi espalhado. Observe pela equação 2.5 que a interação Compton diminui a energia do fóton e que a fração de energia espalhada, $E_{s c} / E_{0}$, depende do ângulo de espalhamento e do parâmetro de colisão $\alpha$. Todos os valores de $\theta$ são possíveis, desde $\theta=0$, limite no qual não ocorreria espalhamento, até $\theta=\pi$, limite que ocorreria retroespalhamento. Na Tabela 2.2 temos as energias dos fótons incidentes e quanto dessa energia é passada para o fóton-Compton quando este é espalhado em ângulos de $90^{\circ}$ e $180^{\circ}$ (backscattering).

A probabilidade de ocorrer espalhamento Compton é proporcional ao número de elétrons por grama. O número de elétrons por grama é praticamente constante na maioria dos materiais (Tabela 2.3) com exceção do hidrogênio, o qual, por ter falta de nêutrons, possui o dobro da densidade eletrônica. Portanto, materiais hidrogenados têm uma probabilidade maior de interação por efeito Compton do que materiais não-hidrogenados de mesma massa. Esta probabilidade também é maior quanto maior a energia do fóton incidente. 
Tabela 2.2. Energias de fótons espalhados por efeito Compton defletidos através de $90^{\circ} \mathrm{e} 180^{\circ}$. A diferença da energia entre fótons incidentes e espalhados é transferida para o elétron-Compton espalhado [30].

\begin{tabular}{lll}
\hline \hline \multirow{2}{*}{ Energia } & \multicolumn{2}{c}{ Energia do fóton espalhado $(\mathrm{keV})$} \\
\cline { 2 - 3 } Incidente $(\mathrm{keV})$ & $90^{\circ}$ & $180^{\circ}$ \\
\hline 60 & 54 & 49 \\
80 & 69 & 61 \\
100 & 84 & 72 \\
120 & 97 & 82 \\
\hline \hline
\end{tabular}

Tabela 2.3. Número de elétrons por grama para vários materiais [37].

\begin{tabular}{lc}
\hline \hline Material & $\mathrm{N}^{\circ}$ Elétrons por grama \\
\hline Gordura & $3,48 \times 10^{23}$ \\
Músculo & $3,36 \times 10^{23}$ \\
Água & $3,34 \times 10^{23}$ \\
Ar & $3,01 \times 10^{23}$ \\
Osso & $3,00 \times 10^{23}$ \\
Chumbo & $2,38 \times 10^{23}$ \\
\hline \hline
\end{tabular}

O espalhamento Compton pode ocorrer com qualquer raio $\mathrm{X}$ diagnóstico e, portanto, é de considerável importância na radiologia. Esta importância contribui negativamente para o contraste, visto que raios $\mathrm{X}$ espalhados borram a imagem, diminuindo a resolução espacial e dificultando o diagnóstico.

\subsection{Avaliação da dose absorvida em CT}

O espalhamento Compton é o principal efeito de interação dos raios X provenientes do tomógrafo, e é responsável pela contribuição considerável à dose 
de radiação nos exames. A radiação espalhada não é confinada ao perfil colimado do feixe como o feixe primário dos raios $\mathrm{X}$, mas forma uma cauda de dose que é conhecida como penumbra (Figura 2.13). Portanto, a aquisição de múltiplos cortes em CT deposita doses em cortes adjacentes devido ao espalhamento dos raios X.

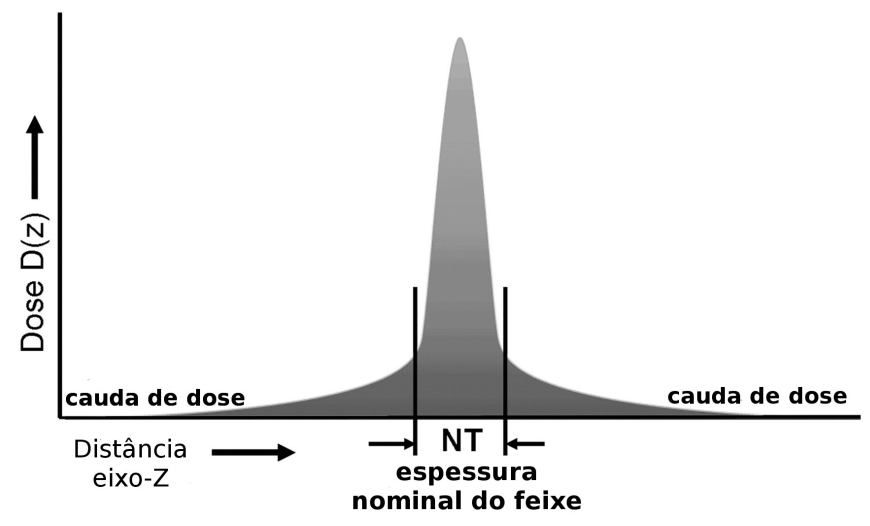

Figura 2.13. Perfil de dose de um único corte feito em $\mathrm{CT}$ com o sensor de radiação posto no centro do objeto simulador. A cauda da dose (penumbra) é devida ao espalhamento Compton.

Se um protocolo no qual dez cortes de $10 \mathrm{~mm}$ fosse realizado em um exame de CT, por exemplo, o quinto corte receberia tanto radiação primária quanto espalhada devido à irradiação, mas também receberia radiação espalhada proveniente do quarto e do sexto cortes; em quantidade menor, receberia também do terceiro e sétimo cortes, e assim por diante (Figura 2.14).

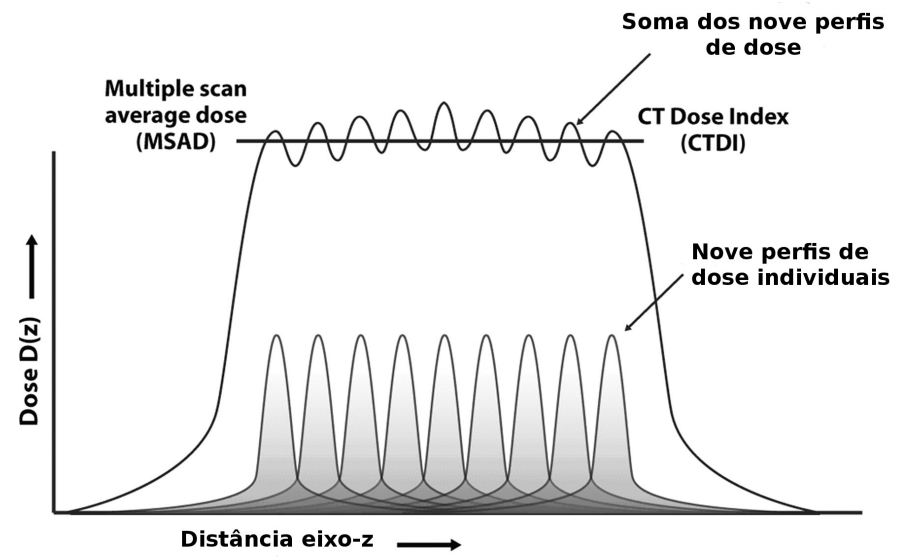

Figura 2.14. Soma de vários perfis de corte dados, um ao lado do outro. O MSAD é o valor médio das intensidades de dose individuais de cada corte, representado na figura pela linha sólida paralela ao eixo- $z$. 
A dose média de múltiplos cortes (MSAD - Multiple Scan Average Dose) é a dose para o tecido que inclui a dose atribuída à radiação espalhada emanada de todos os cortes adjacentes. O MSAD pode ser medido colocando-se uma câmara de ionização tipo lápis em um objeto simulador de acrílico de 16 ou $32 \mathrm{~cm}$ de diâmetro (cabeça e abdômen, respectivamente), realizando uma grande série de cortes adjacentes, e adicionando a dose de todos os cortes.

O MSAD pode ser aproximado a um outro parâmetro chamado índice de dose em tomografia computadorizada, CTDI (Computed Tomography Dose Index), o qual é medido a partir de apenas um corte axial. Diversos índices derivaram do CTDI tais como: $\mathrm{CTDI}_{F D A}, \mathrm{CTDI}_{100}, \mathrm{CTDI}_{\mathrm{w}}, \mathrm{CTDI}_{v o l}$, DLP e MSAD [41]. Neste trabalho utilizaremos os índices $\mathrm{CTDI}_{100}$ e $\mathrm{CTDI}_{\mathrm{w}}$ por serem bem estabelecidos e o procedimento é rotineiramente empregado por físicos médicos para medir dose de radiação em CT $[16,46]$.

A proposta para um índice de dose em CT surgiu em 1981 com Shope et. al. [55], o qual é definido como

$$
C T D I=\frac{1}{T} \int_{-\infty}^{\infty} D(z) d z
$$

sendo $T$ a espessura nominal do corte e $D(z)$ a dose em função da posição ao longo do eixo- $z$ para um perfil de dose de um único corte (ver Figura 2.13). A medida é feita para uma única rotação da fonte de raios $\mathrm{X}$, num dado ponto $(x, y)$, sem movimentação da mesa.

Na prática o CTDI é medido com uma câmara de ionização tipo lápis a qual possui $100 \mathrm{~mm}$ de comprimento sensível, por isso, é denominado de $\mathrm{CTDI}_{100}$. Para calcular o $\mathrm{CTDI}_{100}$, toda deposição de energia ao longo do comprimento da câmara de ionização está relacionada com a espessura de corte da seguinte forma:

$$
C T D I_{100}=\frac{R \times N_{K} \times f_{c}}{T} \times L
$$

sendo $R$ o valor médio de kerma no ar para cada região de interesse (ROI - Region Of Interest), $N_{K}=0,975$ o fator de calibração da câmara em unidades de kerma, na qualidade de feixe apropriada, $f_{c}=0,893 \mathrm{mGy} / \mathrm{mGy}$ é o fator de conversão de kerma no ar para dose absorvida no meio (acrílico), $L$ é o comprimento do volume sensível da câmara de ionização, $T$ é a espessura nominal do corte tomográfico. 
O $\mathrm{CTDI}_{\mathrm{w}}$ representa uma média dos $\mathrm{CTDI}_{100}$ sobre todas as posições $(x, y)$ no objeto simulador para a medida de dose em CT. Com a premissa de que a dose no objeto simulador decai linearmente com a distância radial da superfície para o centro [38], então, a definição de $\mathrm{CTDI}_{\mathrm{w}}$ é

$$
C T D I_{\mathrm{w}}=\frac{1}{3}\left(C T D I_{100}\right)_{\mathrm{centro}}+\frac{2}{3}\left(C T D I_{100}\right)_{\text {periferia }}
$$

A obtenção dos índices $\mathrm{CTDI}_{100}$ e $\mathrm{CTDI}_{\mathrm{w}}$ é feita na prática utilizando-se detectores de radiação ionizante e os protocolos de controle de qualidade em CT que recomendam que câmaras de ionização sejam utilizadas, podendo também serem utilizados filmes, TLD e OSL $[44,4,50,52]$.

Neste trabalho foi feito o uso da câmara de ionização para obtenção dos índices acima citados e também dos dosímetros químicos filme e FBXG, este último pela primeira vez utilizado para tal fim.

\subsection{Dosímetros}

\section{Câmara de ionização}

A câmara de ionização consiste em um detector de radiação tipo capacitor preenchido à gás, o qual possui dois eletrodos que uma vez submetidos a uma diferença de potencial cria um campo elétrico capaz de atrair as cargas produzidas no ar ou gás do volume sensível da câmara. Assim, a carga pode ser medida e é linearmente dependente da dose absorvida. Além desta dependência também há aquelas em função da energia e da taxa de dose do feixe [3]. Por este motivo, a câmara de ionização deve ser selecionada para ser utilizada num feixe particular. Neste trabalho utilizaremos a câmara de ionização tipo lápis para as medidas de distribuição de dose nos objetos simuladores.

\section{Filme Radiocrômico}

Os filmes Gafchromic ${ }^{\circledR}$ (radiocrômicos) possuem propriedades particulares adequadas para dosimetria e aplicações médicas. Eles sofrem uma mudança de coloração logo após serem irradiados e não necessitam de processamento químico pós-irradiação. A relativa insensibilidade à luz ambiente facilita a manipulação e a aplicação desses filmes em serviços de radioterapia ou radiologia [49]. No entanto, ele é 
particularmente sensível a comprimentos de onda curtos (luz azul e ultra-violeta) sendo aconselhável guardar os filmes em lugares escuros para não absorver essa componente proveniente de lâmpadas fluorescentes ou luz solar que passam pela janela. É necessário uma exposição constante durante 125 dias a uma lâmpada fluorescente para que sua densidade óptica aumente e seja comparável à densidade óptica de um filme irradiado com 0,5 Gy.

Outras vantagens que os filmes radiocrômicos possuem são a independência energética no intervalo de $50 \mathrm{keV}$ até ordens de $\mathrm{MeV}$, resistência à água, número atômico efetivo igual a 6, 84 [42], próximo ao de tecido mole, possibilidade de leitura com espectrofotômetro, densitômetro, scanners de filme e a técnica fotográfica, desenvolvida e usada neste trabalho.

A maior desvantagem do filme é o custo. Os filmes radiocrômicos são caros e nem todos os serviços de radiologia ou radioterapia conseguem adquirí-lo.

\section{Fricke Gel}

O maior interesse em desenvolver um dosímetro à base de água é o estudo de sistemas biológicos, visto que a água corresponde a $80 \%$ da constituição molecular do nosso corpo [13]. Talvez tenha sido este o pensamento de Hugo Fricke e Sterne Morse quando desenvolveram, em 1927, o dosímetro químico conhecido, atualmente, como Fricke.

A composição desse dosímetro é basicamente água tridestilada, ácido sulfúrico e sulfato ferroso. A interação da radiação ionizante com o dosímetro desencadeia reações químicas (radiólise da água, ver Equação 2.10) dando lugar a espécies reativas. O elétron que deixa a molécula de água é armadilhado entre outras moléculas de água, que devido à sua natureza polar, tem sua parte positiva voltada para o elétron e a parte negativa mais afastada deste (Figura 2.15). Esse arranjo do elétron armadilhado é chamado de elétron aquoso e possui tempo de vida de $1 \mathrm{~ms}$ na água pura [33].

A molécula de água ionizada, $\mathrm{H}_{2} \mathrm{O}^{+}$, se dissocia em um íon $\mathrm{H}^{+}$, que reage com o oxigênio produzindo $\mathrm{HO}_{2} \bullet$, e em um radical hidroxila, $\mathrm{OH} \bullet$, muito reativo. $\mathrm{O}$ radical hidroxila é a espécie reativa mais efetiva em causar danos biológicos, por isso, o estudo da radiólise da água passou a ser intensamente estudado por Fricke e outros pesquisadores para o entendimento dos efeitos biológicos das radiações ionizantes 


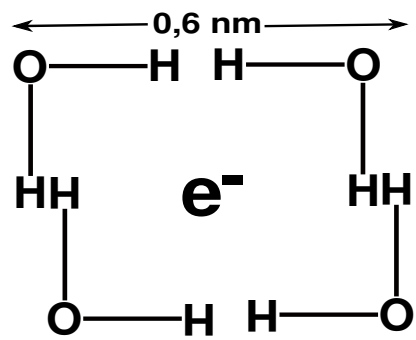

Figura 2.15. Elétron armadilhado por outras moléculas de água. A parte positiva das moléculas de água estão mais próximas do elétron, enquanto que as partes negativas se encontram mais afastadas deste. Este arranjo é chamado de elétron aquoso e ele é detectado, pois possui forte absorção em $720 \mathrm{~nm}$.

$[34,56]$. Essas espécies reagem com os íons ferrosos produzindo íons férricos por diferentes reações que competem entre si (Equações 2.12, 2.13, 2.14).

$$
\begin{aligned}
\mathrm{H}_{2} \mathrm{O} & \rightarrow \mathrm{H}_{2} \mathrm{O}^{+}+e_{a q}^{-} \\
\mathrm{H} \bullet \mathrm{O}_{2} & \rightarrow \mathrm{HO}_{2} \bullet \\
\mathrm{Fe}^{+2}+\mathrm{OH} \bullet & \rightarrow \mathrm{Fe}^{+3}+\mathrm{OH}^{-} \\
\mathrm{Fe}^{+2}+\mathrm{HO}_{2} \bullet & \rightarrow \mathrm{Fe}^{+3}+\mathrm{HO}_{2}^{-} \\
\mathrm{HO}_{2}^{-}+\mathrm{H}_{3} \mathrm{O}^{+} & \rightarrow \mathrm{H}_{2} \mathrm{O}_{2}+\mathrm{H}_{2} \mathrm{O}, \quad \mathrm{e} \\
\mathrm{Fe}^{+2}+\mathrm{H}_{2} \mathrm{O}_{2} & \rightarrow \mathrm{Fe}^{+3}+\mathrm{OH} \bullet+\mathrm{OH}^{-}
\end{aligned}
$$

O FBX (Fricke-Benzóico-Xilenol) desenvolvido por Gupta é o dosímetro Fricke padrão modificado pela adição do quelante alaranjado de xilenol (AX) e do ácido benzóico [25]. O AX melhorou a estabilidade da informação espacial da dose, reduzindo o coeficiente de difusão dos íons férricos, e também alterou o espectro de absorção do Fricke pela formação do complexo $\left[\mathrm{Fe}^{+3}-A X\right]$, o qual deslocou o pico de absorção para $585 \mathrm{~nm}$ (região visível) [54]. Para ratificar a importância do AX, Gupta mostrou que conforme a concentração de AX reduz para zero, a concentração de íons férricos aumenta $\sim 50 \%$ [24], diminuindo a capacidade de leitura óptica do dosímetro. A adição de ácido benzóico aumentou a oxidação radiolítica de íons ferrosos melhorando a sensibilidade para baixas doses.

Gore [22] introduziu pela primeira vez uma matriz gelatinosa ao dosímetro para avaliar a distribuição espacial da dose e quantificá-la por ressonância magnética. É a quantificação do complexo $\left[\mathrm{Fe}^{+3}-\mathrm{AX}\right]$ produzido que fornece a dose absorvida pelo dosímetro. Logo depois, Olsson [47] realizou estudos sobre a influência da gelatina 
na resposta da dose utilizando a ressonância magnética para medir a variação da resposta. A adição da gelatina mantém a resolução da informação espacial por mais tempo e, assim como o xilenol, reduziu a difusão dos íons férricos. Devido à adição de gelatina ao FBX, este dosímetro passou a ser chamado de Fricke Benzóico Xilenol Gel (FBXG) [6].

Apesar da tradicional dosimetria química Fricke utilizar o sulfato ferroso para se ligar ao marcador metálico, qualquer elemento químico passível de ser oxidado com eficiência devido à radiação ionizante, também pode ser utilizado [2]. Neste trabalho utilizaremos o FBXG, na sua composição original, para as medidas de distribuição da dose nos objetos simuladores e avaliação de outros parâmetros em tomografia computadorizada. 


\section{Capítulo}

\section{Materiais e Métodos}

\subsection{Fonte de radiação e objetos simuladores}

Para irradiação dos dosímetros utilizou-se o aparelho de Tomografia Computadorizada Multislice GE Lightspeed + 64 canais pertencente à Central de Diagnóstico Ribeirão Preto (CEDIRP).

Foram fabricados dois objetos simuladores em acrílico: um de cabeça (Figura 3.1(a)) e outro elíptico (Figura 3.1(b)), respectivamente com $16 \mathrm{~cm}$ de diâmetro e $10 \mathrm{~mm}$ de espessura (caminho óptico) e 19,4 ×29,5 $\mathrm{cm}^{2}$ e $10 \mathrm{~mm}$ de espessura, os quais foram preenchidos com o dosímetro FBXG e entrepostos aos seus respectivos objetos espalhadores (Figura 3.2).

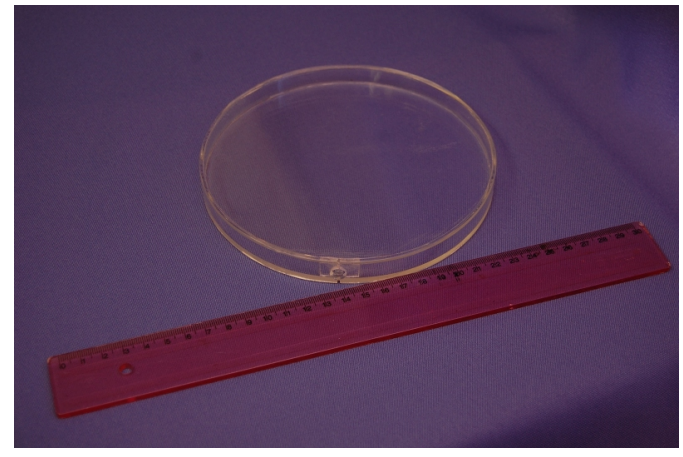

(a)

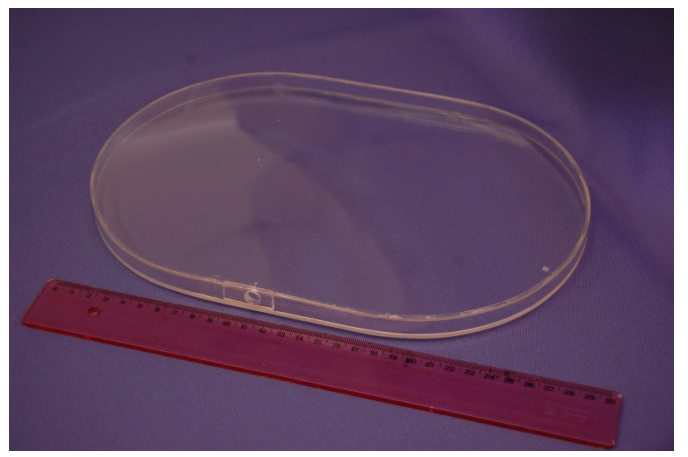

(b)

Figura 3.1. Objetos simuladores de (a) cabeça e (b) abdômen que foram preenchidos com o dosímetro FBXG para avaliação das curvas de isodose e dos índices de dose tomográficos.

O objeto simulador de $16 \mathrm{~cm}$ de diâmetro foi colocado entre dois outros objetos 


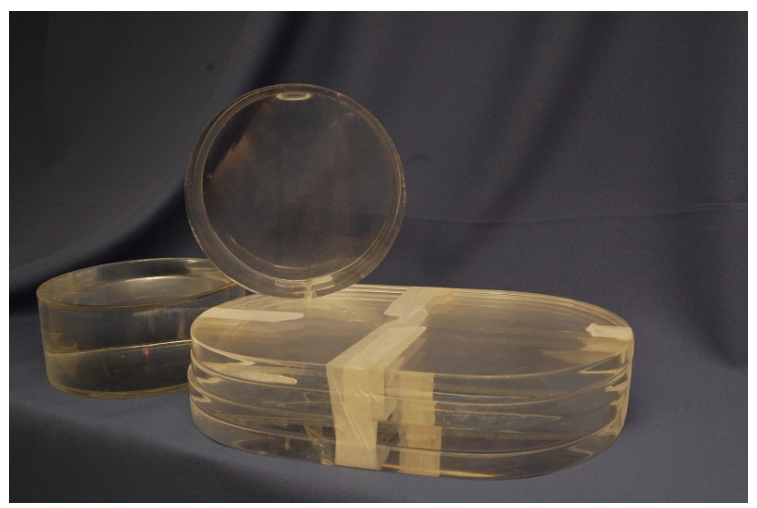

Figura 3.2. Dois objetos espalhadores circulares de $16 \mathrm{~cm}$ de diâmetro e $70 \mathrm{~mm}$ de espessura e quatro elípticos de acrílico maciços cada um com 19,4×29,5 cm² e $15 \mathrm{~mm}$ de espessura.

espalhadores cilíndricos com $70 \mathrm{~mm}$ de espessura cada, preenchidos com água (Figura 3.3(a)). Analogamente, o objeto simulador elíptico foi entreposto a dois outros tomos semelhantes de acrílico maciço com $30 \mathrm{~mm}$ de espessura cada.

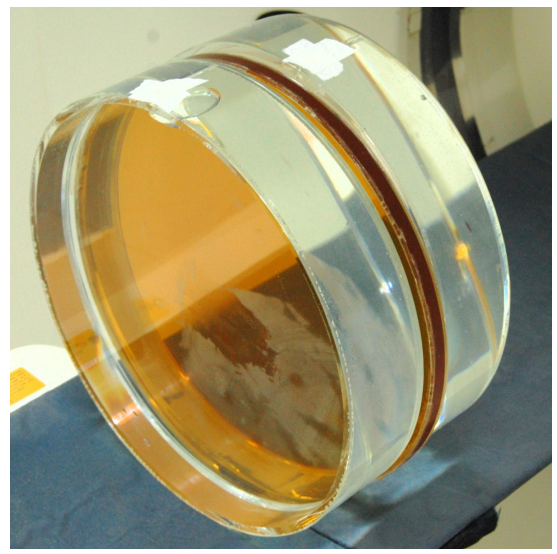

(a)

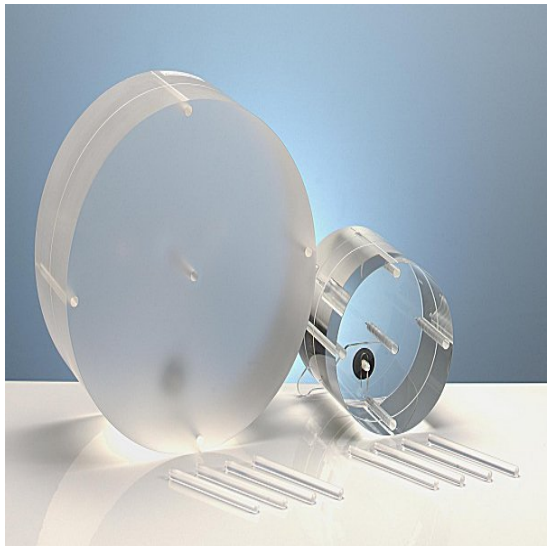

(b)

Figura 3.3. (a) Objeto simulador preenchido com o dosímetro FBXG entreposto aos objetos espalhadores com mesma dimensão. (b) Objetos simuladores padrão em CT com 16 e $32 \mathrm{~cm}$ de diâmetro.

Os objetos simuladores padrões de acrílico para controle de qualidade em CT, dimensões de 16 e $32 \mathrm{~cm}$ de diâmetro (Figura 3.3(b)), foram usados para fazer as medidas com a câmara de ionização. 


\subsection{Dosímetros Utilizados}

Neste trabalho foram utilizados os dosímetros FBXG, o filme Gafchromic ${ }^{\circledR}$ EBT2 QD ${ }^{+}$com dimensões 8" × 10" LOT \# F10070902B e a câmara de ionização Radcal ${ }^{\circledR} / 10 \mathrm{X} 5$-3CT, pertencente à empresa MS Medical Support, para suas validações.

\section{Fricke Benzóico Xilenol Gel}

O dosímetro químico FBX, no estado líquido, foi desenvolvido por Gupta em 1974 e possui a seguinte composição: $0,2 \mathrm{mM}$ de alaranjado de xilenol, 0,2 $\mathrm{mM}$ de sulfato ferroso de amônio, $25 \mathrm{mM}$ de ácido sulfúrico, 5,0 $0 \mathrm{mM}$ de ácido benzóico e água Milli-Q [23, 25]. Essa receita foi modificada pelo grupo Radiare sendo adicionada a gelatina suína 270 Bloom (marca Gelnex) e devido à adição da gelatina, este dosímetro é chamado de Fricke Benzóico Xilenol Gel (FBXG). A quantidade deste último componente é de 124, $38 \mathrm{mM}$ e a solução final do dosímetro é composta por 96\% de água Milli-Q.

Para o preparo do FBXG dissolve-se a quantidade de ácido benzóico em "banho-maria" em torno de $60^{\circ} \mathrm{C}$. Enquanto é dissolvido, metade do volume da solução final é misturada à quantidade de gelatina para que esta absorva a água. Após o ácido benzóico ter sido dissolvido e a mistura gelatina e água ter sido dissolvida à baixa temperatura $\left(35^{\circ} \mathrm{C}\right)$, as duas soluções são misturadas. Em seguida, a quantidade de ácido sulfúrico é colocada nessa última solução para deixar o meio mais ácido para a adição do alaranjado de xilenol. Depois do alaranjado de xilenol, é adicionado o sulfato ferroso amoniacal. Ao fim do preparo, as cubetas e os objetos simuladores são preenchidos com o dosímetro e mantidos em um refrigerador e no escuro até suas irradiações.

Uma curva de calibração com os parâmetros de 120 kV, 300 mAs e espessura de corte de $10 \mathrm{~mm}$ foi feita com cubetas padrão de acrílico posicionadas no ar e no isocentro do aparelho. As dimensões das cubetas são $45 \times 10 \times 10 \mathrm{~mm}^{3}$ (Figura 3.4(a)). A variação da dose absorvida foi obtida aumentando-se o número de revoluções, cortes axiais, em uma mesma posição (mesa fixa). 


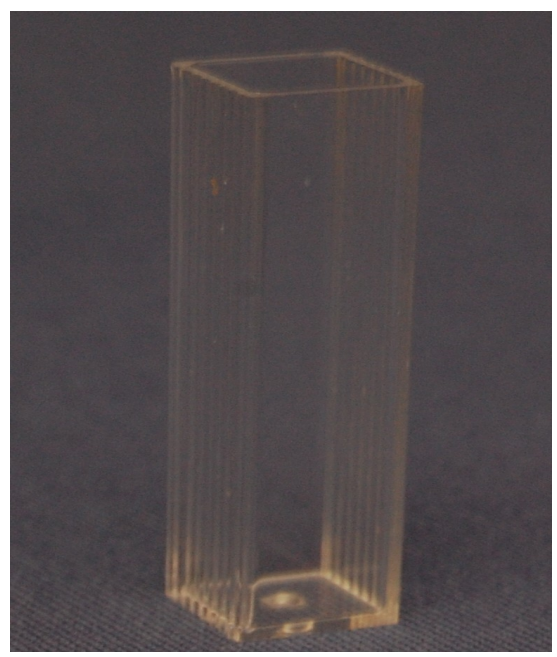

(a)

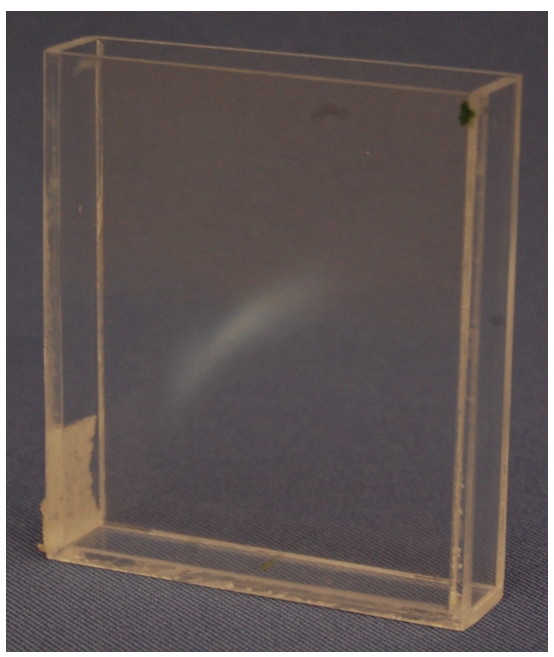

(b)

Figura 3.4. Cubetas (a) padrão e (b) retangular utilizdas para curva de calibração e avaliação da espessura e homogeneidade de corte, respectivamente.

Cubetas de acrílico retangulares com dimensões $70 \times 50 \times 10 \mathrm{~cm}^{3}$ (Figura 3.4(b)) também foram fabricadas e preenchidas com o dosímetro FBXG. Essas foram utilizadas para avaliação das espessuras de corte de 5, 10 e $20 \mathrm{~mm}$, e da homogeneidade do corte transaxial.

A avaliação das curvas de isodose foi feita com a irradiação do FBXG dentro dos objetos simuladores cilíndrico e elíptico. O objeto simulador de cabeça foi posto sobre um suporte de cabeça e, o de abdômen, sobre a mesa do aparelho de CT. Nas irradiações ambos estavam entrepostos aos respectivos objetos espalhadores.

\section{Filme Radiocrômico}

O filme radiocrômico foi recortado em tiras de aproximadamente $5 \times 3,5 \mathrm{~cm}^{2}$ para realizar a curva de calibração, medidas da espessura de corte e homogeneidade de campo. Para a curva de calibração, a irradiação da primeira tira foi feita sobre a mesa e, em seguida, as demais tiras foram empilhadas, sucessivamente, umas sobre as outras. Utilizou-se os parâmetros de 120 kV, 300 mAs e 10 mm de espessura de corte, variando o número de cortes de 5 a 25 sobre a mesma área da tira. Desta maneira, a primeira tira irradiada recebeu maior dose (25 cortes), pois fez a integração da dose das demais. 
As irradiações para a espessura de corte foi feita sobre a mesa com as espessuras nominais de corte de 5, 10 e $20 \mathrm{~mm}$, mantendo os demais parâmetros do aparelho fixos ( $\mathrm{kV}$ e mAs). Para cada espessura de corte, a tira do filme recebeu 5 cortes sobre uma mesma área. A avaliação da homogeneidade de campo foi feita com a mesma tira da espessura de corte.

As curvas de isodose foram feitas recortando os filmes no mesmo formato dos objetos simuladores (cilíndrico e elíptico). Devido ao filme radiocrômico ter dimensões menores que o objeto simulador elíptico, este foi recortado para ter as dimensões da metade direita do objeto simulador. Em seguida os filmes foram irradiados paralelamente ao feixe de raios $\mathrm{X}$, usando os mesmos parâmetros da curva de calibração, entrepostos aos dois respectivos objetos espalhadores. Após irradiação do filme semielíptico, a imagem foi processada e espelhada para se ter a imagem completa no formato elíptico.

\section{Câmara de Ionização}

As medições com a câmara de ionização foram realizadas no ar para fazer a curva de calibração da leitura da dose em função do número de revoluções do tubo e dentro dos objetos simuladores usuais (16 e $32 \mathrm{~cm}$ de diâmetro) para avaliar a dose nas regiões de interesse (ROIs).

Para as medições da curva de calibração e dos índices de dose em tomografia utilizou-se os parâmetros de 120 kV, 300 mAs e espessura de corte de $10 \mathrm{~mm}$. Para avaliar a mudança da dose com a espessura de corte, foi feita também uma medição no centro dos objetos simuladores com uma espessura de corte de $20 \mathrm{~mm}$ e os demais parâmetros mantidos fixos.

\subsection{Métodos de Avaliações}

\section{Fotografia}

As imagens dos dosímetros, filme e FBXG, foram feitas por um dispositivo de carga acoplada - sensor CCD, charge-coupled device - (dimensões de 23, $7 \times 15,6 \mathrm{~mm}^{2}$ ) de uma câmara fotográfica Nikon/D40 (6,1 megapixels) com uma fonte de luz branca,

a uma distância câmara fotográfica-dosímetro fixa. No registro feito das imagens (sensor CCD), também a velocidade do obturador, a abertura do diafragma e a 
sensibilidade do sensor foram mantidas fixas para garantir boa reprodutibilidade.

A absorbância foi calculada das imagens da câmara via lei de Lambert-Beer. Para tal, um programa feito em MATLAB ${ }^{\circledR}$ foi desenvolvido pelo grupo. Este programa faz leituras das imagens pré-irradiada e pós-irradiada levando em consideração as intensidades dos pixeis de cada uma, com resolução espacial máxima de 0,1mm [53]. Para melhor leitura das intensidades de pixel nos dosímetros, um filtro alaranjado (combinação do sistema de cores RGB) foi implementado ao programa.

Na Figura 3.5 está representado o sistema de leitura fotográfico. Uma fonte de luz intensa, localizada na parte inferior do sistema, está conectada à câmara fotográfica e é acionada no disparo do obturador. O sensor da câmara registra o sinal e este é passado para o computador para se fazer a análise no programa desenvolvido em MATLAB.

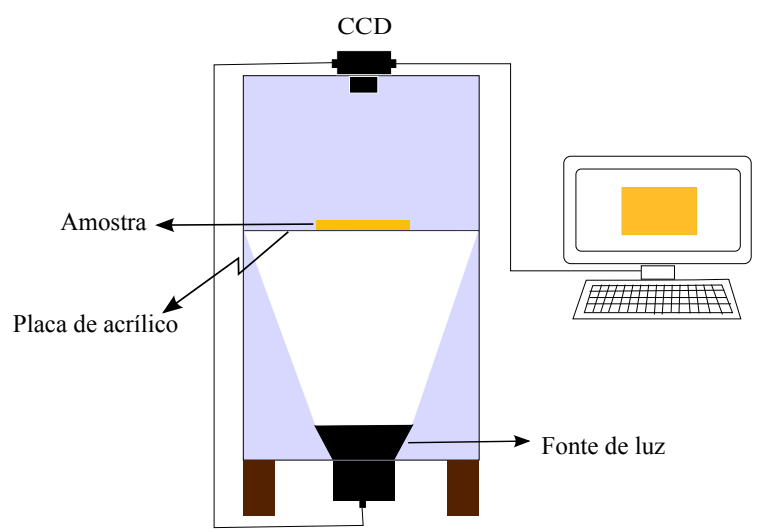

Figura 3.5. Esquema do funcionamento do sistema de leitura fotográfico.

A propagação de incertezas para a absorbância via método fotográfico é dada pela equação

$$
\sigma_{A}^{2}=\frac{1}{\ln 10} \cdot\left(\frac{\sigma_{I_{0 t}}^{2}}{I_{0}^{2}}+\frac{\sigma_{I_{t}}^{2}}{I^{2}}\right)
$$

sendo $\sigma_{I_{0 t}}^{2}$ a incerteza total da intensidade inicial, $\sigma_{I_{t}}^{2}$ a incerteza total da intensidade final, $I_{0}$ e $I$ as intensidades iniciais e finais dos pixeis, respectivamente.

\section{Espectroscopia óptica}

A análise espectrofotométrica dos dosímetros FBXG e filme foram realizadas no espectrofotômetro Beckman Coulter/DU 640 no modo absorbância. Para os dois dosímetros a medição de referência do espectrofotômetro foi feita com ar. 


\section{Densitometria óptica}

Os filmes utilizados para a curva de calibração foram avaliados com um densitômetro Victoreen ${ }^{\circledR}$ Modelo 07 - 443. Cada ponto de leitura do filme foi avaliado três vezes para se fazer uma média e tirar o desvio padrão. 


\section{Capítulo}

\section{Resultados e Discussões}

Uma das relações mais importantes na dosimetria é a resposta do dosímetro com a quantidade de energia absorvida proveniente da radiação nele incidente. Esta resposta, idealmente, deve ser linear para facilitar um planejamento radioterápico ou otimizar a melhoria da qualidade da imagem em radiodiagnóstico.

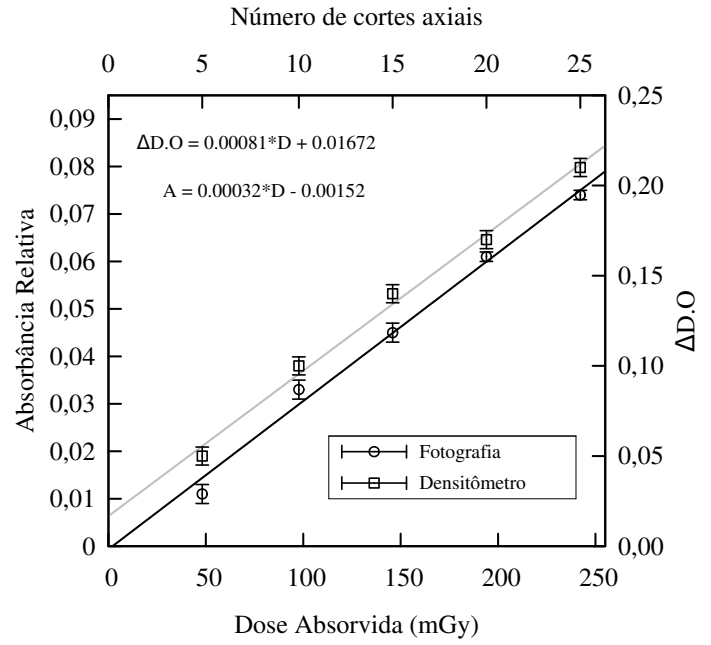

(a)

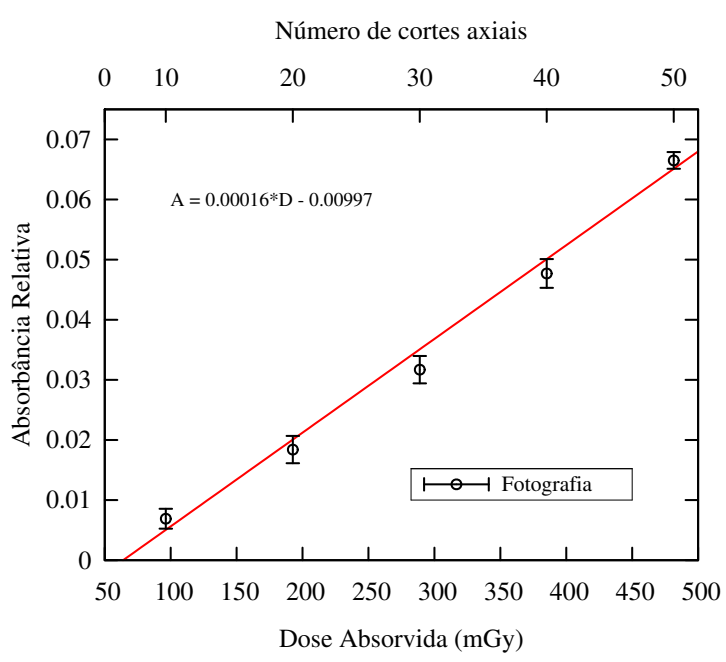

(b)

Figura 4.1. Curvas de calibração obtidas para os dosímetros (a) filme e (b) FBXG através da irradiação de várias amostras de cada dosímetro. Para o filme foram usados os métodos de avaliação de densitometria óptica e fotografia. Para o FBXG utilizou-se apenas fotografia.

$\mathrm{Na}$ Figura 4.1(a) temos as respostas do filme radiocrômico exposto a um feixe de radiação do tomógrafo, utilizando os parâmetros 120 kV, 300 mAs e 10 mm de espessura de corte, energia efetiva $\sim 70 \mathrm{keV}[31,12,41]$, em termos de absorbância relativa e densidade óptica versus dose absorvida. Para essas curvas de calibração, 
utilizou-se os parâmetros geralmente empregados em exames de cabeça e próximo daquele utilizado em exames de abdômen [51, 28, 43, 27]. A câmara de ionização foi utilizada como sistema de referência para determinar as doses absorvidas.

As curvas de calibração mostram relações lineares entre absorbância relativa e dose absorvida, assim como, variação da densidade óptica e dose absorvida no filme radiocrômico. A dose absorvida é também linear em função do número de cortes axiais realizados pelo tomógrafo, sendo um corte equivalente à 9,63 mGy (calibrado com a câmara de ionização tipo lápis), para a técnica descrita acima. A absorbância relativa foi obtida pelo método fotográfico, descrito anteriormente e a densidade óptica foi medida com o densitômetro. Desses resultados podemos inferir que os comportamentos das leituras são semelhantes e, assim, a técnica fotográfica pode ser utilizada para as demais leituras.

A Figura 4.1(b) mostra a relação entre absorbância relativa e dose absorvida para o dosímetro FBXG quando irradiado com a mesma técnica usada no filme. A leitura do dosímetro foi feita com a técnica fotográfica, o qual apresentou comportamento linear para o intervalo de dose prescrito e para o intervalo de energia na faixa do radiodiagnóstico.

O filme radiocrômico foi selecionado para comparação entre as medições por possuir caraterísticas ópticas semelhantes às do dosímetro químico FBXG, em um determinado intervalo do espectro visível, por ser de fácil manipulação (não necessita ser processado) e ter baixa sensibilidade à luz visível.

Nas Figuras 4.2(a) e 4.2(b) observa-se que tanto o Fricke gel (FBXG sem a adição de ácido benzóico) quanto o filme radiocrômico possuem picos significativos entre $420 \mathrm{~nm}$ e $440 \mathrm{~nm}$ e outro por volta de $585 \mathrm{~nm}$. O pico em $585 \mathrm{~nm}$ é secundário para o filme em vista do expressivo aumento em $634 \mathrm{~nm}$, conforme aumenta-se a dose absorvida. O Fricke gel, no entanto, aumenta sua absorbância consideravelmente em $585 \mathrm{~nm}$ devido ao aumento no número de íons $\left[\mathrm{Fe}^{+3}\right]$ produzidos se ligarem ao marcador metálico, alaranjado de xilenol. Com o aumento na produção de íons férricos há uma diminuição dos íons ferrosos existentes, por isso a diminuição do pico em $442 \mathrm{~nm}$. Apesar de não ter sido feita a curva de absorbância do FBXG, este apresenta comportamento óptico semelhante ao Fricke gel.

Na Figura 4.3 tem-se os resultados da homogeneidade nos cortes transaxiais 


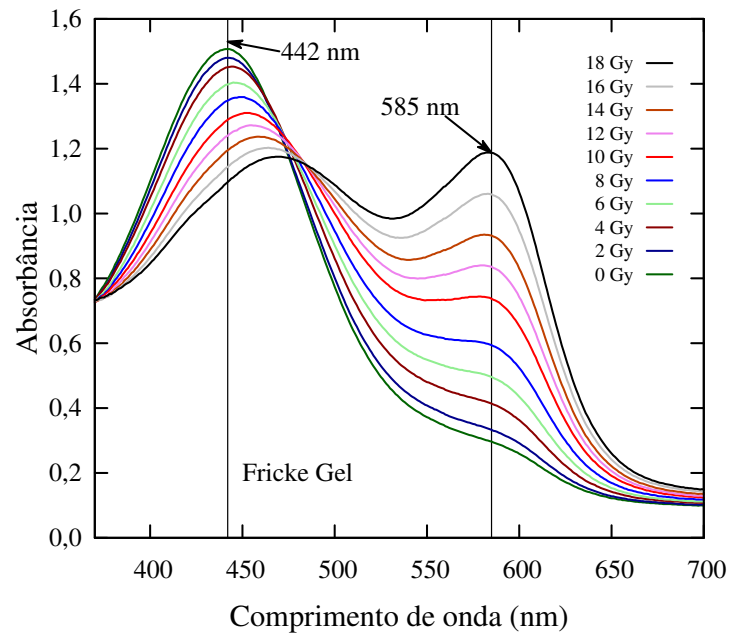

(a)

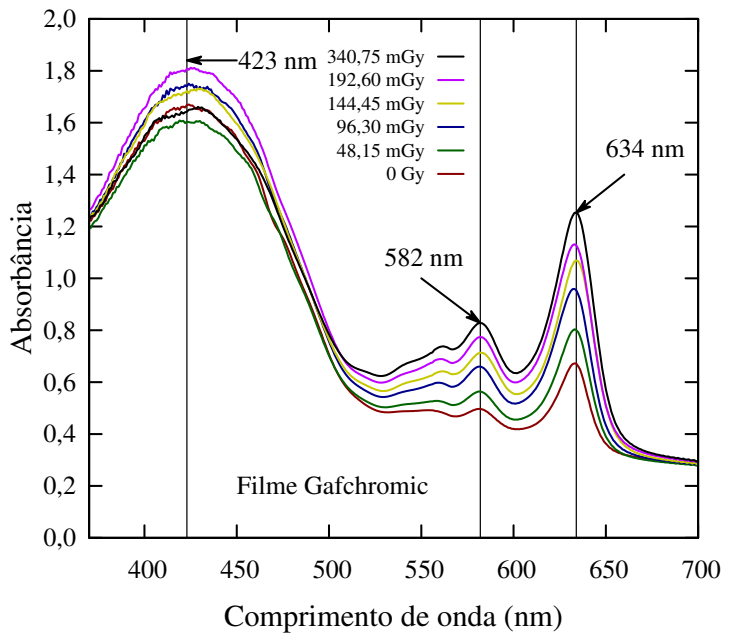

(b)

Figura 4.2. Medições espectrofotométricas dos dosímetros químicos (a) Fricke gel e (b) filme radiocrômico em função do comprimento de onda e dose absorvida de um feixe de radiação.

para o filme e o FBXG. As espessuras de corte selecionadas foram de 5, 10 e $20 \mathrm{~mm}$. A avaliação da homogeneidade foi realizada utilizando-se o método fotográfico em ambos os dosímetros.
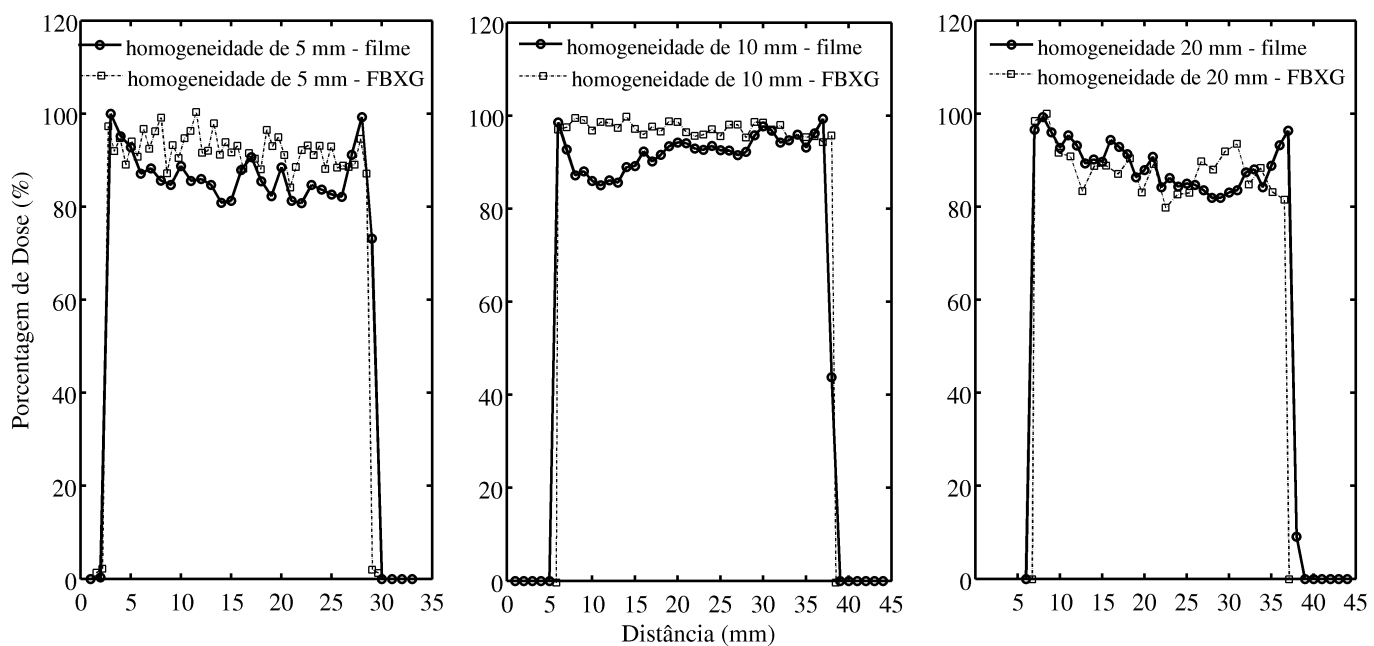

Figura 4.3. Resultados da avaliação da homogeneidade das espessuras de corte, utilizando os dosímetros filme radiocrômico e FBXG.

Observa-se em quase todos os gráficos da Figura 4.3 uma diminuição da porcentagem de dose na parte central da região transaxial do corte, possivelmente 
devido a uma maior aproximação do tubo às extremidades. Medindo-se a densidade óptica do filme, via densitômetro, obtém-se variações de $10 \%$ a $20 \%$ dos valores das extremidades, corroborando com os valores obtidos via técnica fotográfica. Considerando apenas a correção geométrica da irradiação do filme, devido ao inverso do quadrado da distância, o feixe apresentaria uma diminuição da sua intensidade de $\sim 10 \%$ entre a extremidade do filme e sua parte central. No gráfico central onde se avalia a espessura de $10 \mathrm{~mm}$, o FBXG apresentou uma homogeneidade mais uniforme comparada àquelas do mesmo dosímetro para as espessuras de corte de 5 e $20 \mathrm{~mm}$, corroborando com as medidas obtidas com sensor gel e técnica de ressonância magnética [27].

A espessura de corte nominal do tomógrafo foi analisada, via técnica fotográfica, utilizando-se também os dois dosímetros. Na Figura 4.4 tem-se os perfis axiais de cortes nominais de 5, 10 e $20 \mathrm{~mm}$. Cada perfil foi retirado da região central da cubeta ou filme, perpendicular ao corte.

Os valores de espessura de corte foram obtidos através da distância, paralela ao eixo- $x$, da largura à meia altura do patamar do perfil da espessura de corte (FWHM Full Width at Half Maximum).
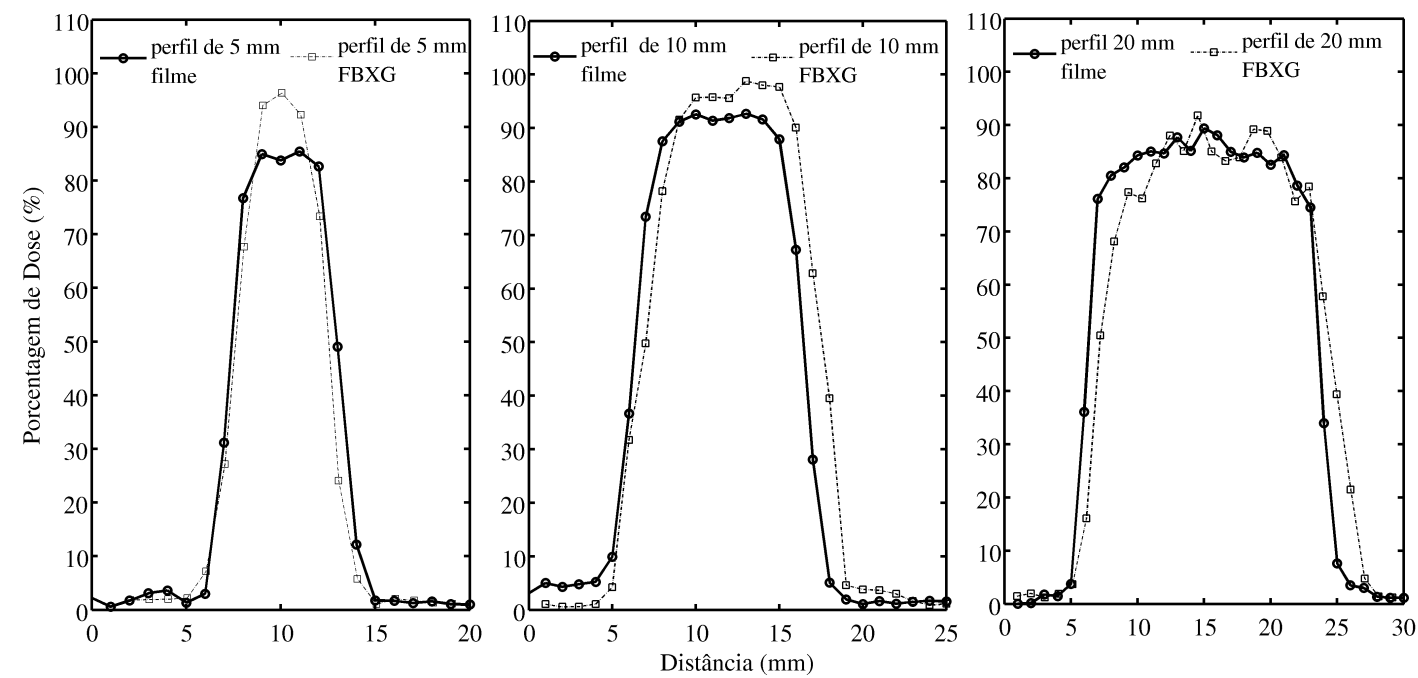

Figura 4.4. Perfis axiais de cortes de feixes do CT para os dosímetros FBXG e filme, variando a espessura de corte.

Os valores de FWHM para cada perfil de espessura de corte e os dosímetros utilizados estão na Tabela 4.1. Segundo a Agência Nacional de Vigilância Sanitária 
[1], admite-se uma diferença percentual de 20\%, $10 \%$ e 5\% para cortes nominais (selecionados no aparelho) de 5, 10 e $20 \mathrm{~mm}$, respectivamente. O FBXG apresentou diferenças percentuais relativas aos valores nominais de $2 \%, 4 \%$ e $5,5 \%$ para as espessuras de corte de 5, 10 e $20 \mathrm{~mm}$, respectivamente. O filme apresentou diferenças percentuais relativas aos valores nominais de $18 \%, 2 \%$ e $11 \%$, para as espessuras de corte de 5, 10 e $20 \mathrm{~mm}$, respectivamente. Portanto, usando o método fotográfico ambos dosímetros apresentaram resultados equivalentes e, segundo a ANVISA, apenas para as espessuras de corte de 5 e $10 \mathrm{~mm}$.

Tabela 4.1. Valores nominais da espessura de corte do aparelho de CT comparados com os valores de FWHM medidos, associados às suas incertezas, para o filme radiocrômico e o FBXG.

\begin{tabular}{ccc}
\hline \hline Valor Nominal & \multicolumn{2}{c}{ FWHM } \\
\cline { 2 - 3 } Espessura (mm) & Filme (mm) & FBXG (mm) \\
\hline 5 & $5,9 \pm 0,4$ & $4,9 \pm 0,4$ \\
10 & $10,2 \pm 0,4$ & $10,4 \pm 0,4$ \\
20 & $17,8 \pm 0,4$ & $21,1 \pm 0,4$ \\
\hline \hline
\end{tabular}

Os aparelhos de tomografia computadorizada irradiam girando o tubo $360^{\circ}$ ao redor do objeto/paciente, apresentando assim, teoricamente, um gradiente de dose simetricamente circular com maior intensidade na circunferência próxima a entrada da pele e menor na circunferência central.

A Figura 4.5(a) mostra as curvas de isodose do filme quando irradiado com os parâmetros de $120 \mathrm{kV}, 300 \mathrm{mAs}$ e $10 \mathrm{~mm}$ de espessura de corte. O filme foi recortado com o mesmo diâmetro do objeto simulador de cabeça, $16 \mathrm{~cm}$.

A posição de irradiação do filme foi paralela ao feixe de fótons do tomógrafo justamente para avaliar as isodoses. Este tipo de irradiação em CT não é comum, mas já foi usado para tal fim [9]. Verifica-se o comportamento circular com diminuição da intensidade do círculo mais externo para o mais interno. A medição da absorbância no centro da Figura 4.5(a) corresponde em média a $72 \%$ dos valores da periferia. Teoricamente, esses valores deveriam ser iguais e não apresentar gradiente 

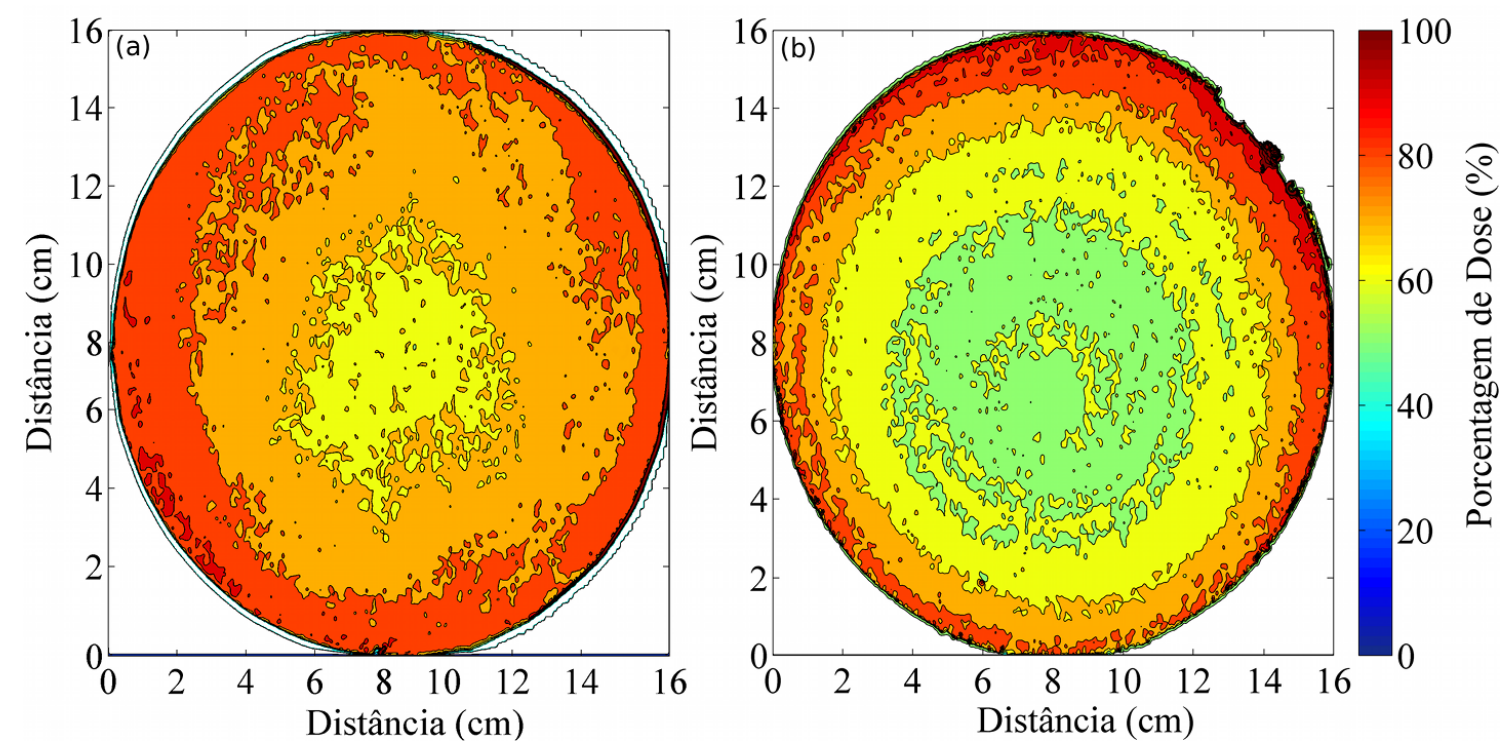

Figura 4.5. Distribuição da dose absorvida (a) no filme radiocrômico e (b) no FBXG, para o objeto simulador de $16 \mathrm{~cm}$ de diâmetro.

de dose [43].

Com os parâmetros de $120 \mathrm{kV}, 300 \mathrm{mAs}$ e $10 \mathrm{~mm}$ de espessura de corte, o FBXG foi irradiado, Figura 4.5(b), e obteve-se o mesmo padrão circular, com regiões de maior porcentagem de dose na superfície e menor na parte central do objeto simulador. Observa-se na parte superior do FBXG irradiado uma região maior com maior porcentagem de dose do que na parte inferior. Isto se deve à atenuação da radiação provocada pelo suporte no qual objetos espalhadores e o objeto simulador foram postos.

Na Figura 4.6, o filme radiocrômico foi irradiado com os mesmos parâmetros usados no filme circular, porém, um maior número de cortes axiais foi dado a este com formato elíptico. Observa-se várias curvas de isodose bem delimitadas na parte superior do filme, região onde se teve uma maior porcentagem de dose $(\sim 90 \%)$. Na metade inferior do filme, as curvas de isodose são menos acentuadas, revelando a diminuição da intensidade do feixe devido à atenuação da mesa.

Devido à sensibilidade do filme radiocrômico, pôde-se obter um gradiente de dose variando desde $90 \%$, na parte superior, até 30\% na região central. O valor de porcentagem de dose na região central é metade daquela, para a mesma região, no filme de cabeça. Temos então, a influência do tamanho do objeto simulador/paciente 
na dose. Na Tabela 4.2 são apresentados os valores medidos de absorbância e os valores calculados do índice de dose em tomografia.

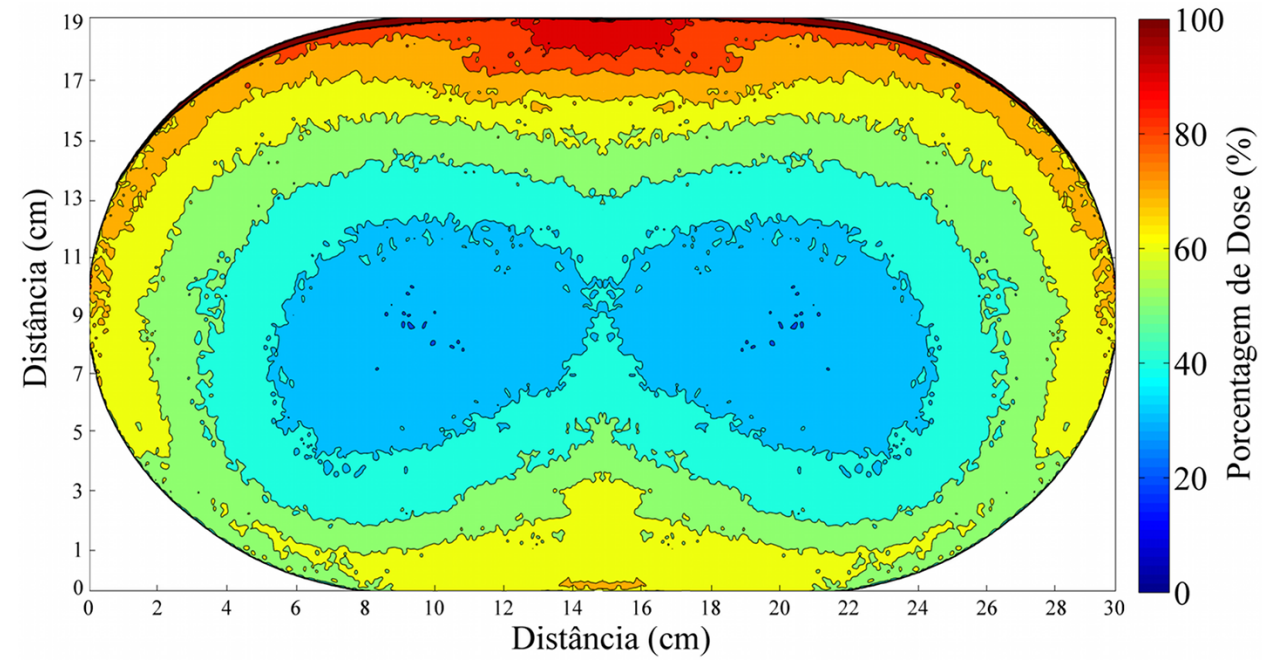

Figura 4.6. Distribuição da dose absorvida no filme radiocrômico quando inserido entre os objetos espalhadores elípticos de acrílico.

No objeto simulador de abdômen, preenchido com FBXG, Figura 4.7, observa-se as curvas de isodose mais claramente na parte superior deste. Na parte inferior, observa-se uma descontinuidade dessas curvas devido a atenuação da mesa.

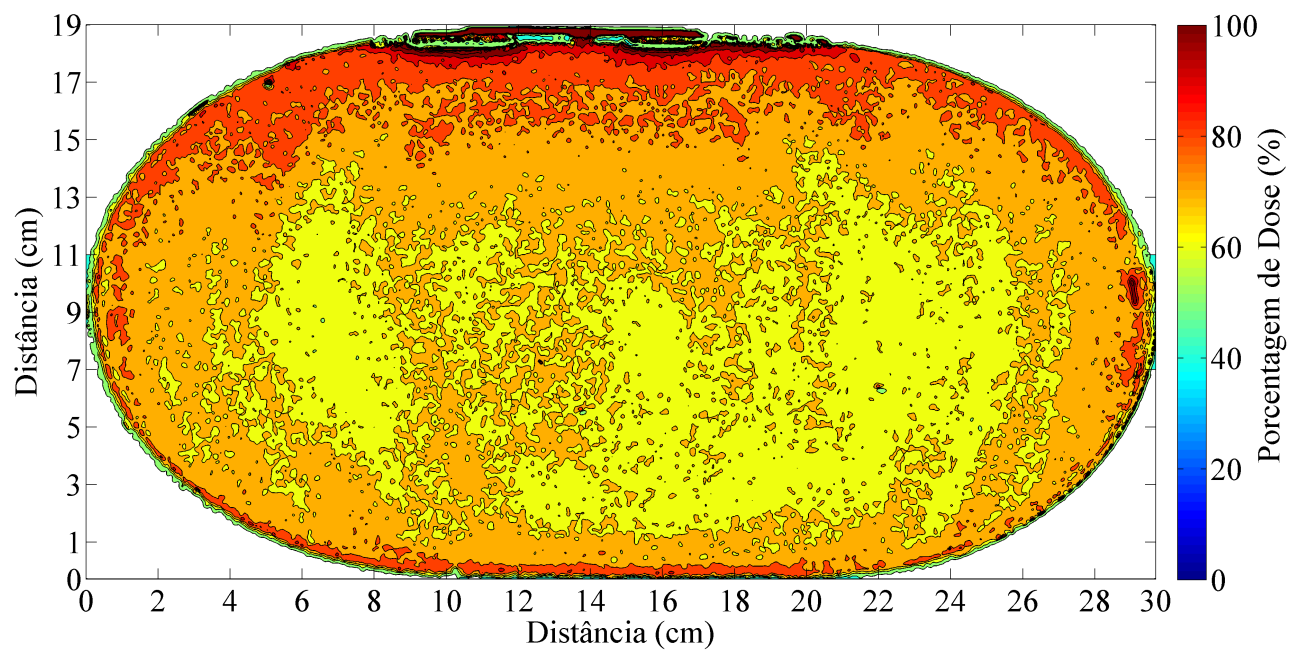

Figura 4.7. Distribuição da dose absorvida no objeto simulador homogêneo de abdômen, preenchido com o dosímetro FBXG.

Por ter um formato elíptico, as curvas de isodose no objeto simulador de abdômen adquiriram uma forma diferente e já não se observa um padrão geométrico no centro 
do objeto simulador como se observou naquele de cabeça. A mesma dose dada ao objeto simulador de cabeça foi dada ao de abdômen, no entanto, as dimensões deste último são maiores, ocasionando uma maior atenuação dos raios $\mathrm{X}$, quando o feixe está em direções paralelas ao eixo- $x$. Logo, para um mesmo ponto na periferia, por exemplo o ponto D na Figura 4.8, a contribuição para a dose absorvida neste ponto, quando o tubo está na direção oposta, próxima ao ponto B, é menor do que a contribuição que o ponto A recebe quando o tubo está próximo ao ponto C. Por isso, poucas curvas de isodose são observadas no objeto simulador de abdômen, quando comparado ao objeto simulador de cabeça preenchido com FBXG, onde se tem a mesma distância em todas as direções radiais.
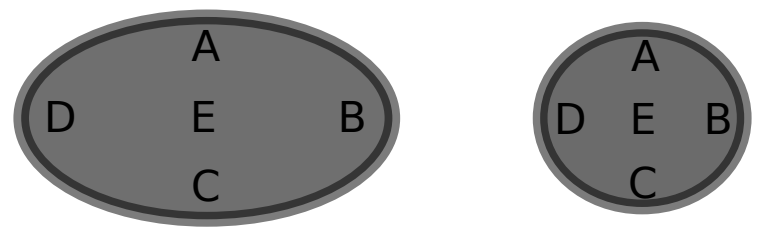

Figura 4.8. Cinco regiões de interesse localizadas nos objetos simuladores de abdômen e cabeça.

As absorbâncias relativas das regiões de interesse (ROI - Region Of Interest), Figura 4.8, foram inferidas dos gráficos das Figuras 4.5, 4.6 e 4.7 e são apresentadas na Tabela 4.2 .

Tabela 4.2. Absorbâncias relativas inferidas das imagens fotográficas dos filmes radiocrômicos e dos objetos simuladores preenchidos com FBXG, considerando as cinco regiões de interesse.

\begin{tabular}{cccccc}
\hline \hline & \multicolumn{2}{c}{ Filme } & & \multicolumn{2}{c}{ FBXG } \\
\cline { 2 - 3 } \cline { 5 - 6 } ROI & Circular & Elíptico & & Circular & Elíptico \\
\hline A & 0,024 & 0,074 & & 0,015 & 0,018 \\
B & 0,019 & 0,048 & & 0,016 & 0,016 \\
C & 0,021 & 0,051 & & 0,011 & 0,015 \\
D & 0,024 & 0,048 & & 0,015 & 0,017 \\
E & 0,016 & 0,033 & & 0,006 & 0,014 \\
\hline \hline
\end{tabular}


A partir desses valores de absorbância e das equações das retas retiradas das curvas de calibração, pôde-se inferir os valores dos índices de dose em tomografia $\left(\mathrm{CTDI}_{100}\right.$ e $\left.\mathrm{CTDI}_{\mathrm{w}}\right)$, tanto para o filme quanto para o FBXG. Esses valores calculados estão na Tabela 4.3 e as expressões para o cálculo dos índices estão no Capítulo 2.

Tabela 4.3. Índices de dose tomográficos inferidos das imagens fotográficas dos filmes radiocrômicos e dos objetos simuladores (circular e elípticos) preenchidos com FBXG, considerando as cinco regiões de interesse.

\begin{tabular}{|c|c|c|c|c|c|c|c|c|}
\hline \multirow[b]{3}{*}{ ROI } & \multicolumn{4}{|c|}{ Filme } & \multicolumn{4}{|c|}{ FBXG } \\
\hline & \multicolumn{2}{|c|}{$\mathrm{CTDI}_{100}$} & \multicolumn{2}{|c|}{$\mathrm{CTDI}_{\mathrm{w}}$} & \multicolumn{2}{|c|}{$\mathrm{CTDI}_{100}$} & \multicolumn{2}{|c|}{$\mathrm{CTDI}_{\mathrm{w}}$} \\
\hline & Circ. & Elíptico & Circ. & Elíptico & Circ. & Elíptico & Circ. & Elíptico \\
\hline A & 53,41 & 51,37 & 47,83 & 42,07 & 22,65 & 25,12 & 19,92 & 23,99 \\
\hline B & 42,95 & 33,68 & 40,86 & 30,28 & 23,55 & 23,55 & 20,53 & 22,95 \\
\hline $\mathrm{C}$ & 47,13 & 35,72 & 43,64 & 31,64 & 19,02 & 22,65 & 17,51 & 22,35 \\
\hline $\mathrm{D}$ & 53,41 & 33,68 & 47,83 & 30,28 & 22,65 & 24,46 & 19,93 & 23,55 \\
\hline $\mathrm{E}$ & 36,67 & 23,48 & - & - & 14,48 & 21,74 & - & - \\
\hline
\end{tabular}

Comparando os valores de $\mathrm{CTDI}_{100}$ e $\mathrm{CTDI}_{\mathrm{w}}$ do filme radiocrômico, Tabela 4.3, calculados através da absorbância relativa com o método fotográfico, com aqueles medidos com a câmara de ionização, Tabela 4.4, estes aprensentaram concordância com diferença percentual de 10\% para o objeto simulador de cabeça padrão. Apesar de não poder ser feita uma comparação direta com o objeto simulador de abdômen padrão, os valores do objeto simulador de abdômen elíptico apresentaram coerência. A dimensão do eixo menor da elípse é próxima daquela do objeto simulador de cabeça e do eixo maior próxima daquela do objeto simulador de abdômen padrão, portanto, os índices de dose para este objeto elíptico são uma mistura entre os dois objetos padrão.

Os índices de dose em tomografia para o FBXG não apresentaram valores próximos daqueles esperados para os objetos simuladores de cabeça e abdômen. Esta 
discrepância pode ser devido aos objetos simuladores terem sido preenchidos com receitas diferentes e irradiados em dias diferentes, pois várias irradiações em cada objeto simulador, após um dia inteiro de expediente na clínica podem comprometer o tomógrafo. No entanto, os valores estão coerentes no que diz respeito à simetria destes objetos.

Na Tabela 4.4 estão os valores calculados dos índices de dose em tomografia medidos com a câmara de ionização tipo lápis inserida nas ROIs dos dois objetos simuladores homogêneos de acrílico, 16 e $32 \mathrm{~cm}$ de diâmetro. Como previsto anteriormente pelas curvas de isodose no $\mathrm{FBXG}$, no ponto $\mathrm{C}$, em ambos objetos simuladores, foi medida uma dose inferior em relação aos demais pontos periféricos. A mesa, apesar de ser feita de um material de baixo número atômico, interfere no feixe de radiação atenuando levemente. Na prática, os exames de CT são feitos usando uma técnica de modulação de $\mathrm{mA}$ para corrigir este efeito. O próprio aparelho regula o $\mathrm{mA}$ em regiões que necessitem de mais fótons para manter a qualidade de imagem.

Tabela 4.4. Valores dos índices de dose em tomografia calculados a partir dos valores medidos da dose absorvida $\left(\mathrm{D}_{\mathrm{abs}}\right)$ nos objetos simuladores de CT com a câmara de ionização. Os valores de dose e dos índices estão em mGy. Os parâmetros utilizados foram de $120 \mathrm{kV}, 300 \mathrm{mAs}$ e $10 \mathrm{~mm}$ de espessura de corte.

\begin{tabular}{|c|c|c|c|c|c|c|}
\hline \multirow[b]{2}{*}{ ROI } & \multicolumn{3}{|c|}{$16 \mathrm{~cm}$ de diâmetro } & \multicolumn{3}{|c|}{$32 \mathrm{~cm}$ de diâmetro } \\
\hline & $\mathrm{D}_{\mathrm{abs}}(\mathrm{mGy})$ & $\mathrm{CTDI}_{100}$ & $\mathrm{CTDI}_{\mathrm{w}}$ & $\mathrm{D}_{\mathrm{abs}}(\mathrm{mGy})$ & $\mathrm{CTDI}_{100}$ & $\mathrm{CTDI}_{\mathrm{w}}$ \\
\hline $\mathrm{A}$ & 6,82 & 59,38 & 55,78 & 3,52 & 30,65 & 25,28 \\
\hline B & 6,35 & 55,29 & 53,05 & 3,53 & 30,73 & 25,33 \\
\hline $\mathrm{C}$ & 5,63 & 49,02 & 48,87 & 3,13 & 27,25 & 23,01 \\
\hline $\mathrm{D}$ & 6,16 & 53,63 & 51,95 & 3,65 & 31,78 & 26,03 \\
\hline $\mathrm{E}$ & 5,58 & 48,58 & - & 1,67 & 14,54 & - \\
\hline $\mathrm{E}(20 \mathrm{~mm})$ & 9,66 & 42,05 & - & 2,90 & 12,62 & - \\
\hline
\end{tabular}

Comparando o valor da dose no ponto A entre os objetos simuladores de 16 e 32 cm de diâmetro, o valor da dose em $32 \mathrm{~cm}$ é praticamente a metade do valor daquela 
em $16 \mathrm{~cm}$. Como dito anteriormente, por ter menor dimensão o objeto de $16 \mathrm{~cm}$, quando o tubo está na posição $\mathrm{C}$, permite que um maior número de fótons chegue ao ponto A. Por isso, apesar de uma maior aproximação do tubo com o detector, devido às dimensões do objeto simulador de $32 \mathrm{~cm}$ de diâmetro, os valores de dose neste objeto simulador é menor. Assim, para os mesmos parâmetros tomográficos, o tamanho do objeto simulador/paciente influencia a dose absorvida e esse fator deve ser considerado ao selecionar os parâmetros para pacientes adultos que tenham dimensões abdominais e toráxicas diferentes.

Medições de dose obtidas no centro de um objeto simulador de abdômen são, em teoria, $50 \%$ dos valores medidos na periferia, enquanto que para o objeto simulador de cabeça, as leituras no centro e periferia são aproximadamente as mesmas [43]. Na Tabela 4.4, temos os valores de dose medidos com a câmara de ionização, os quais estão de acordo com a previsão teórica [43]. Para o objeto de $16 \mathrm{~cm}$ de diâmetro o valor da leitura no centro, ponto E, corresponde em média a $90 \%$ do valor medido nas quatro regiões periféricas. No objeto de $32 \mathrm{~cm}$ de diâmetro o valor da leitura corresponde, em média, a $48 \%$ do valor medido nas quatro regiões periféricas. Quando se aumenta a espessura de corte o valor da dose absorvida aumenta proporcionalmente. Este valor no ponto E para um corte de $10 \mathrm{~mm}$ é de 5, $58 \mathrm{mGy}$. Neste mesmo ponto, mas para uma espessura de corte de $20 \mathrm{~mm}$, o valor da dose absorvida é de 9,66 mGy. Como foi dobrada a abertura do colimador, o valor da dose é quase o dobro, devido ao aumento da fluência de fótons que chega ao detector. No entanto, os valores dos índices tomográficos são quase os mesmos, pois este é normalizado pela espessura de corte. 


\section{Capítulo}

\section{Conclusões}

Dos resultados das medidas realizadas com o dosímetro FBXG, para avaliar se ele é adequado para obtenção de parâmetros para testes de controle de qualidade e aceitação de um equipamento de tomografia computadorizada, tem-se que:

O FBXG pode ser considerado um dosímetro promissor a ser utilizado em CT, uma vez que apresenta resposta linear com a dose absorvida e pode ser utilizado para obtenção da maioria dos parâmetros acima citados.

A técnica fotográfica empregada aos dosímetros FBXG e filme mostrou-se válida ao ser comparada com a densitometria óptica. Os dois dosímetros aprensentaram comportamento linear em função da dose absorvida, o que é desejável em dosimetria. Também é uma técnica rápida de se fazer a leitura, de baixo custo quando comparada à espectrofotometria óptica e ao valor de um scanner de leitura do filme radiocrômico. A grande vantagem de se utilizar esta técnica de leitura em CT, associada aos dosímetros FBXG e filme, é que com apenas uma medição (uma foto) obtém-se dados para perfil de dose de um determinado corte, perfil de dose transaxial e mapas de dose bidimensionais, ao contrário da câmara de ionização, a qual consegue fazer somente leituras pontuais da dose absorvida e em pontos fixos nos objetos simuladores. Além disso, ela não consegue avaliar os parâmetros espessura de corte e homogeneidade de campo.

Aplicada à dosimetria gel, outra vantagem da técnica fotográfica é que o sinal pode ser armazenado para posteriormente ser analisado a qualquer momento. Assim, o grande problema da dosimetria gel, difusão e oxidação natural dos íons com o tempo e temperatura, é eliminado.

Os valores da espessura de corte, obtidos através de medidas realizadas com o 
FBXG e filme, propiciou observar que o primeiro dosímetro se presta igualmente ao filme para obtenção desse parâmetro. Embora diferenças de 17\%, 2\%, 16\% foram apresentadas entre esses dosímetros, respectivamente para espessuras nominais de 5, 10 e $20 \mathrm{~mm}$, foi aquele que forneceu os valores mais próximos daqueles nominais, ou seja, 4, 9, 10, 4 e 21, $1 \mathrm{~mm}$.

Os valores da homogeneidade de campo, obtidos através dos dois dosímetros, também permitiu observar que o gel também se presta igualmente para obtenção desse parâmetro. Das leituras médias obtidas dos dois dosímetros nos patamares dos perfís dos campos respectivamente $92,10 \% \pm 3,23 \%, 97,43 \% \pm 1,49 \%$ e $88,08 \% \pm$ $5,12 \%$ para o FBXG e $86,96 \% \pm 5,29 \%, 92,33 \% \pm 3,92 \%$ e $88,89 \% \pm 5,23 \%$ para o filme para os campos de 5, 10 e $20 \mathrm{~mm}$. Considerando as incertezas associadas a essas médias, o FBXG apresenta uma maior homogeneidade de campo.

O filme e o FBXG mostraram através das curvas de isodose que a mesa do CT, apesar de ser feita de baixo número atômico, atenua o feixe de radiação acarretando uma diminuição da dose absorvida na região próxima à mesa.

As medidas pontuais com a câmara de ionização ratificaram as medições feitas com o filme e o FBXG, mostrando a diminuição da dose na ROI próxima à mesa.

Os valores dos índices de dose calculados através da absorbância no FBXG não apresentaram consistência com as medições feitas com a câmara de ionização e com o filme. No entanto, o dosímetro mostrou-se promissor em mostrar comportamento das curvas de isodose dentro de diferentes objetos simuladores quando irradiados com CT.

As propostas futuras deste trabalho são: estudo da dosimetria específica do FBXG para CT (em comparação com o filme) para obtenção dos índices de dose, melhorias da composição do FBXG para aumentar sua sensibilidade com a radiação ionizante na faixa do radiodiagnóstico, no arranjo experimental fotográfico e na leitura das imagens, e avaliação dos demais parâmetros que podem influenciar a dose absorvida usando esses e outros objetos simuladores. 


\section{Referências Bibliográficas}

[1] ANVISA. Radiodiagnóstico médico: Segurança e desempenho de equipamentos. 2005. 35

[2] F. H. Attix, John W. Boag, Robert A. Dudley, E. W. Emery, J. F. Fowler, Hugo Fricke, S. Genna, Edwin J. Hart, John S. Laughlin, and Wolfgang J. Ramm. Radiation Dosimetry, volume 2. Academic Press, second edition edition, 1966. 23

[3] Frank Herbert Attix. Introduction to Radiological Physics and Radiation Dosimetry. Wiley-VCH Verlag GmbH \& Co. KGaA, 2004. 2, 13, 20

[4] J. A. Bauhs, T. J. Vrieze, A. N. Primak, M. R. Bruesewitz, and C. H. McCollough. Ct dosimetry: comparison of measurement techniques and devices. Radiographics, 28(1):245-253, 2008. 20

[5] M. A. Bero. Dosimetric properties of a radiochromic gel detector for diagnostic x-rays. Nuclear Instruments \& Methods in Physics Research Section A - Accelerators Spectrometers Detectors and Associated Equipment, 580(1):186-189, 2007. 2

[6] M. A. Bero, W. B. Gilboy, P. M. Glover, and J. L. Keddie. Three-dimensional radiation dose measurements with ferrous benzoic acid xylenol orange in gelatin gel and optical absorption tomography. Nuclear Instruments \& Methods in Physics Research Section A-Accelerators Spectrometers Detectors and Associated Equipment, 422(1-3):617-620, 1999. 2, 23

[7] D. Biswas, J. E. Bible, M. Bohan, A. K. Simpson, P. G. Whang, and J. N. Grauer. Radiation exposure from musculoskeletal computerized tomographic 
scans. Journal of Bone and Joint Surgery-American Volume, 91A(8):1882-1889, 2009. 1

[8] R. N. Bracewell. Strip integration in radio astronomy. Australian Journal of Physics, 9:198-217, 1956. 4

[9] S. Brady, T. Yoshizumi, G. Toncheva, and D. Frush. Implementation of radiochromic film dosimetry protocol for volumetric dose assessments to various organs during diagnostic ct procedures. Medical Physics, 37(9):4782-4792, September 2010. 35

[10] D. J. Brenner and E. J. Hall. Current concepts - computed tomography - an increasing source of radiation exposure. New England Journal of Medicine, $357(22): 2277-2284,2007.1$

[11] J. T. Bushberg. The aapm/rsna physics tutorial for residents - x-ray interactions. Radiographics, 18(2):457-468, 1998. xi, 13, 14, 16

[12] Jerrold T. Bushberg, J. Anthony Seibert, Edwin M. Leidholdt Jr., and John M. Boone. The Essential Physics of Medical Imaging. Lippincott Williams \& Wilkins, second edition edition, 2002. x, 8, 31

[13] Stewart C. Bushong. Radiologic Science for Technologists: Physics, Biology, and Protection. C. V. Mosby Company, fourth edition edition, 1988. 21

[14] A. M. F. Caldeira, A. de Almeida, A. M. Neto, M. L. Baesso, A. C. Bento, and M. A. Silva. Fricke xylenol gel characterization using a photoacustic technique. Nuclear Instruments \& Methods in Physics Research Section A-Accelerators Spectrometers Detectors and Associated Equipment, 582(2):484-488, 2007. 2

[15] A. M. F. Caldeira, A. M. Neto, A. C. Bento, M. L. Baesso, M. A. Silva, and A. de Almeida. Behavior of oxidation in the radiochromic gel dosimeter through photoacoustic technique measurements. Applied Radiation and Isotopes, 65(5):605-609, 2007. 2

[16] Robert Y.L. Chu, Jane Fisher, Benjamin R. Archer, Burton J. Conway, Mitchell M. Goodsitt, Sharon Glaze, Joel E. Gray, and Keith J. Strauss. Aapm 
report 31: Standardized methods for measuring diagnostic x-ray exposures. American Association of Physicists in Medicine, pages 1 - 20, 1990. 2, 19

[17] European Comission. Quality criteria for computed tomography. EUR 16262 EN, 1999. 2

[18] National Research Council. Health Risks from Exposure to Low Levels of Ionizing Radiation: BEIR VII Phase 2. Washington, DC: The National Academy, 2006. Committee to Assess Health Risks from Exposure to Low Levels of Ionizing Radiation. 2

[19] H. Cramér and H. Wold. Some theorems on distribution functions. Journal of the London Mathematical Society, s1-11:290-294, 1936. 4

[20] D. J. De Rosier and A. Klug. Reconstruction of three dimensional structures from electron micrographs. Nature, 217(5124):130-134, January 1968. 4

[21] G. Gambarini, C. Birattari, M. Mariani, R. Marchesini, L. Pirola, P. Prestini, M. Sella, and S. Tomatis. Study of light transmittance from layers of fricke-xylenol-orange-gel dosimeters. Nuclear Instruments \& Methods in Physics Research Section B - Beam Interactions with Materials and Atoms, 213:321-324, 2004. 2

[22] J.C. Gore, Y.S. Kang, and R.J. Schulz. Measurement of radiation dose distributions by nmr imaging. Magnetic Resonance Imaging, 2(3):244 - 244, 1984. Third Annual Meeting of the Society for Magnetic Resonance Imaging. 22

[23] B. L. Gupta. Absorption characteristics of xylenol orange. Talanta, 21(6):683-684, 1974. 26

[24] B. L. Gupta, R. M. Bhat, G. R. Narayan, and B. Susheela. Acid and xylenol orange effects in the fbx dosimeter. International Journal of Applied Radiation and Isotopes, 34(6):887-890, 1983. 22 
[25] B. L. Gupta and K. R. Gomathy. Consistency of ferrous sulfate benzoic-acid-xylenol orange dosimeter. International Journal of Applied Radiation and Isotopes, 25(11-1):509-513, 1974. 22, 26

[26] E. J. Hall and D. J. Brenner. Cancer risks from diagnostic radiology. British Journal of Radiology, 81(965):362-378, 2008. 1

[27] B. Hill, A. J. Venning, and C. Baldock. A preliminary study of the novel application of normoxic polymer gel dosimeters for the measurement of ctdi on diagnostic x-ray ct scanners. Medical Physics, 32(6):1589-1597, 2005. 32, 34

[28] W. Huda, J. Chang, K. A. Lieberman, and M. L. Roskopf. Radiation dose and image quality in head ct examinations. Radiology, 221:160-160, November 2001. 32

[29] W. Huda, E. M. Scalzetti, and M. Roskopf. Effective doses to patients undergoing thoracic computed tomography examinations. Medical Physics, 27(5):838-844, 2000. 2

[30] Walter Huda and Richard Slone. Review of Radiologic Physics. Lippincott Williams \& Wilkins, second edition edition, 2003. xiv, 15, 17

[31] J. Janeczek and F. Pernicka. The measurement of ct scanner radiation-dose profile using tl dosimeters. Radiation Protection Dosimetry, 60(3):231-235, 1995. 31

[32] K. A. Jessen, P. C. Shrimpton, J. Geleijns, W. Panzer, and G. Tosi. Dosimetry for optimisation of patient protection in computed tomography. Applied Radiation and Isotopes, 50(1):165-172, 1999. 1

[33] Harold Elford Johns and John Robert Cunningham. The Physics of Radiology. Charles C. Thomas, fourth edition, 1983. 21

[34] C. D. Jonah. A short history of the radiation-chemistry of water. Radiation Research, 144(2):141-147, 1995. 22

[35] Kenneth R. Kase, Bengt E. Bjärngard, and Frank Herbert Attix. The Dosimetry of Ionizing Radiation, volume I. Academic Press, 1985. 2 
[36] R. G. Kelly, K. J. Jordan, and J. J. Battista. Optical ct reconstruction of 3d dose distributions using the ferrous-benzoic-xylenol (fbx) gel dosimeter. Medical Physics, 25(9):1741-1750, 1998. 2

[37] Faiz M. Khan. The Physics of Radiation Therapy. Lippincott Williams \& Wilkins, third edition edition, 2003. xiv, 17

[38] W. Leitz, B. Axelsson, and G. Szendro. Computed-tomography dose assessment - a practical approach. Radiation Protection Dosimetry, 57(1-4):377-380, 1995. 20

[39] O. W. Linton and F. A. Mettler. National conference on dose reduction in ct, with an emphasis on pediatric patients. American Journal of Roentgenology, 181(2):321-329, August 2003. 1

[40] M. Mahesh. The aapm/rsna physics tutorial for residents - search for isotropic resolution in ct from conventional through multiple-row detector. Radiographics, 22(4):949-962, 2002. x, xi, 5, 6, 9

[41] Cynthia McCollough, Dianna Cody, Sue Edyvean, Rich Geise, Bob Gould, Nicholas Keat, Walter Huda, Phil Judy, Willi Kalender, Mike McNitt-Gray, Rick Morin, Tom Payne, Stanley Stern, Larry Rothenberg, Paul Shrimpton, Jan Timmer, and Charles Wilson. Aapm report 96: The measurement, reporting, and management of radiation dose on ct. American Association of Physicists in Medicine, pages 1-34, 2008. x, 9, 19, 31

[42] E. C. McCullough and T. W. Holmes. Acceptance testing computerized radiation-therapy treatment planning systems - direct utilization of ct scan data. Medical Physics, 12(2):237-242, 1985. 21

[43] M. F. McNitt-Gray. Aapm/rsna physics tutorial for residents: Topics in ct radiation dose in ct1. Radiographics, 22(6):1541-1553, 2002. 1, 11, 32, 36, 41

[44] M. F. McNitt-Gray, C. H. Cagnon, T. D. Solberg, and I. Chetty. Radiation dose in spiral ct: The relative effects of collimation and pitch. Medical Physics, 26(3):409-414, 1999. 20 
[45] W. J. Meredith and J. B. Massey. Fundamental Physics of Radiology. Bristol, 1972. 1

[46] E. Nickoloff and A. Dutta. Influence of phantom diameter, kvp and scan mode upon ct radiation doses. Medical Physics, 29(6):1345-1345, June 2002. 2, 19

[47] L. E. Olsson, S. Petersson, L. Ahlgren, and S. Mattsson. Ferrous sulfate gels for determination of absorbed dose distributions using mri technique - basic studies. Physics in Medicine and Biology, 34(1):43-52, 1989. 22

[48] J. Radon. Über die bestimmung von funktionen durch ihre inegralwerte langs gewisser mannigfaltigkeiten. Mathematisch Physische Klasse Berichte, 69:262-277, 1917. 4

[49] O. Rampado, E. Garelli, S. Deagostini, and R. Ropolo. Dose and energy dependence of response of gafchromic (r) xr-qa film for kilovoltage x-ray beams. Physics in Medicine and Biology, 51(11):2871-2881, June 2006. 20

[50] O. Rampado, E. Garelli, and R. Ropolo. Computed tomography dose measurements with radiochromic films and a flatbed scanner. Medical Physics, 37(1):189-196, 2010. 20

[51] J. Ravenel, E. M. Scalzetti, W. Huda, and W. Garrisi. Radiation exposure and image quality in chest ct examinations. American Journal of Roentgenology, 177(2):279-284, August 2001. 32

[52] C. Ruan, E. G. Yukihara, W. J. Clouse, P. B. R. Gasparian, and S. Ahmad. Determination of multislice computed tomography dose index (ctdi) using optically stimulated luminescence technology. Medical Physics, 37(7):3560-3568, July 2010. 20

[53] R. Sato, A. De Almeida, and M. V. Moreira. (137)cs source dose distribution using the fricke xylenol gel dosimetry. Nuclear Instruments \& Methods In Physics Research Section B-beam Interactions with Materials and Atoms, 267(5):842-845, March 2009. 2, 29 
[54] L. J. Schreiner. Review of fricke gel dosimeters. Journal of Physics: Conference Series, 3:9-21, 2004. 22

[55] T. B. Shope, R. M. Gagne, and G. C. Johnson. A method for describing the doses delivered by transmission-x-ray computed-tomography. Medical Physics, 8(4):488-495, 1981. xi, 12, 19

[56] J. D. Zimbrick. Radiation chemistry and the radiation research society: A history from the beginning. Radiation Research, 158(2):127-140, 2002. 22 